\title{
On the Physics of the Warm Water Volume and EI Niño/La Niña Predictability
}

\author{
ALLAN J. CLARKE ${ }^{\mathrm{a}}$ AND XIAOLIN ZHANG ${ }^{\mathrm{b}}$ \\ Earth, Ocean and Atmospheric Science, Florida State University, Tallahassee, Florida
}

(Manuscript received 19 July 2018, in final form 11 February 2019)

\begin{abstract}
Previous work has shown that warm water volume (WWV), usually defined as the volume of equatorial Pacific warm water above the $20^{\circ} \mathrm{C}$ isotherm between $5^{\circ} \mathrm{S}$ and $5^{\circ} \mathrm{N}$, leads El Niño. In contrast to previous discharge-recharge oscillator theory, here it is shown that anomalous zonal flow acceleration right at the equator and the movement of the equatorial warm pool are crucial to understanding WWV-El Niño dynamics and the ability of WWV to predict ENSO. Specifically, after westerly equatorial wind anomalies in a coupled ocean-atmosphere instability push the warm pool eastward during El Niño, the westerly anomalies follow the warmest water south of the equator in the Southern Hemisphere summer in December-February. With the wind forcing that causes El Niño in the eastern Pacific removed, the eastern equatorial Pacific sea level and thermocline anomalies decrease. Through long Rossby wave dynamics this decrease results in an anomalous westward equatorial flow that tends to push the warm pool westward and often results in the generation of a La Niña during March-June. The anomalously negative eastern equatorial Pacific sea level typically does not change as much during La Niña, the negative feedback is not as strong, and El Niños tend to not follow La Niñas the next year. This El Niño/La Niña asymmetry is seen in the WWV/El Niño phase diagram and decreased predictability during "La Niña-like" decades.
\end{abstract}

\section{Introduction}

Figure 1 shows an updated version of the El Niño/warm water volume (WWV) phase diagram of Meinen and McPhaden (2000) and Kessler (2002) and associated time series. Here El Niño is represented by the El Niño index Niño-3.4, the monthly anomalous sea surface temperature (SST) averaged over the east/central equatorial Pacific region $5^{\circ} \mathrm{S}-5^{\circ} \mathrm{N}, 170^{\circ}-120^{\circ} \mathrm{W}$. The Niño-3.4 data were taken from https://www.cpc.ncep.noaa.gov/products/ analysis_monitoring/ensostuff/detrend.nino34.ascii.txt. Unless otherwise specified, all anomalies in this paper are calculated relative to the years January 1993 December 2016. The WWV is the anomalous monthly equatorial volume above the $20^{\circ} \mathrm{C}$ isotherm in the region $5^{\circ} \mathrm{S}-5^{\circ} \mathrm{N}, 120^{\circ} \mathrm{E}-80^{\circ} \mathrm{W}$, and it is represented by the average depth of the $20^{\circ} \mathrm{C}$ isotherm over this region. The WWV is available at https://www.pmel.noaa.gov/

\footnotetext{
a ORCID: 0000-0002-8558-103X

b ORCID: 0000-0002-8810-8993.
}

Corresponding author: Allan J. Clarke, a.clarke@fsu.edu tao/wwv/data/. Unless noted otherwise, monthly anomalous data are not low-pass filtered.

Consistent with Meinen and McPhaden (2000) and Kessler (2002), the time series in Fig. 1a show that positive WWV (recharge) tends to lead El Niño and negative WWV (discharge) tends to lead La Niña. This corresponds to a clockwise rotation of the (Niño-3.4, WWV) points in the Fig. 1b phase diagram. Such a relationship is fundamental to El Niño prediction, because it suggests that recharge can be used to predict a coming El Niño, and discharge used to predict a coming La Niña [see, e.g., the "FSU Regression" statistical model operational monthly predictions of Clarke and Van Gorder (2003) at https://iri.columbia.edu/our-expertise/climate/forecasts/ enso/current/?enso_tab $=$ enso-sst_table].

The Meinen and McPhaden (2000) and Kessler (2002) phase diagrams are similar in shape to Fig. 1, and these authors have pointed out an asymmetry that occurs in both. Kessler comments that there is "apparently a marked persistence of amplitude for part of the cycle: a large recharge predicts a subsequent large El Niño SST anomaly, and then a large discharge... On the other hand, there is little such persistence from the discharge phase to $\mathrm{La}$ Niña, and virtually no connection between the amplitude 

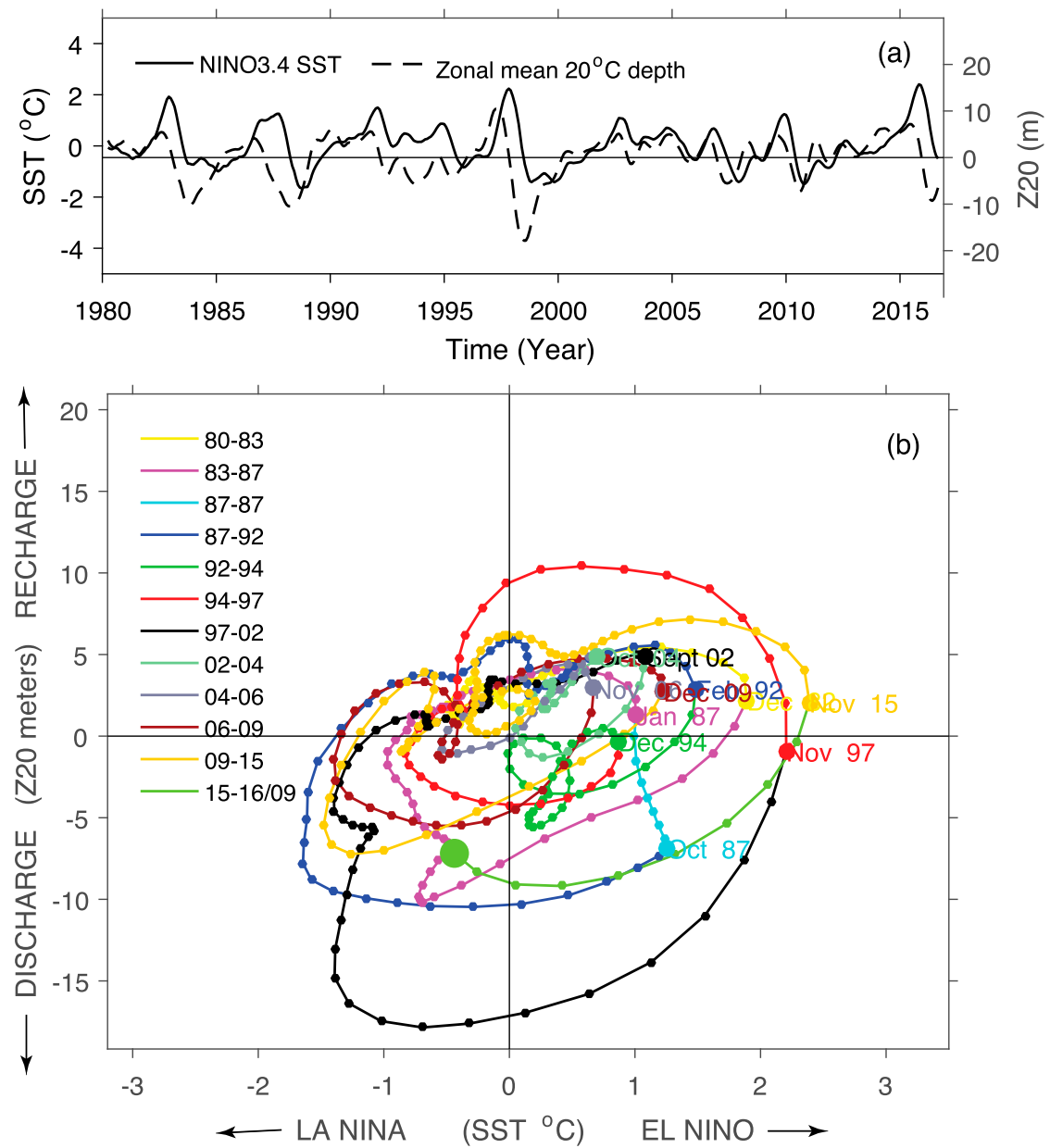

FIG. 1. (a) Time series of Niño-3.4 SST (solid; ${ }^{\circ} \mathrm{C}$; scale at left) and zonal mean $20^{\circ} \mathrm{C}$ isotherm depth (dashed; m; scale at right) anomalies from the average annual cycle, filtered with a 7-month running mean. The axes are scaled so that each time series has equal variance. (b) Phase orbits of the two time series in (a). SST $\left({ }^{\circ} \mathrm{C}\right)$ is plotted along the abscissa, and zonal mean $20^{\circ} \mathrm{C}$ depth $(\mathrm{m})$ along the ordinate. Small dots are drawn at the center of each month. The line color changes at the peak of each El Niño SST maximum, which is also shown as a large dot and its date is labeled. The final point is September 2016, noted with a larger green dot.

of La Niña anomalies and those of the subsequent recharge or El Niño."

Also fundamental to El Niño-Southern Oscillation (ENSO) and its prediction, and not taken into account in Fig. 1, is the seasonal phase locking that occurs during El Niño. Specifically, Fig. 2 [updated from Clarke (2008) and Bunge and Clarke (2009)] shows that, to within an excellent approximation (see Fig. 2c), we may write

$$
\text { Niño3.4 }(m, a)=S(m) Y(a),
$$

where $S(m)$ (see Fig. 2a) is a fixed calendar month structure beginning in April of one calendar year and ending in March of the following year, and $Y(a)$ (see Fig. 2b) is a single annual value for a particular El Niño/ La Niña year $a$ that begins in April of one year and ends in March of the following year. For example, the big El Niño year from April 1997 to March 1998 corresponds to a large positive $Y(a)$, while the big La Niña from April 1988 to March 1989 corresponds to a large negative value of $Y(a)$ and both have the same $S(m)$ phase-locked structure. The phase-locked structure tells us that El Niños and La Niñas tend to have a maximum near the end of the year and that they all can be well approximated by a single annual function $Y(a)$ multiplying a fixed structure function $S(m)$. In this paper we will refer to the months April-March as the "El Niño year."

The spring persistence barrier, first documented by Walker (1924), and now often studied (see, e.g., the review by Clarke 2014), is closely associated with the phase-locked structure described by (1) and the uncertainty in what $Y$ in year $a+1$ will be given $Y$ in year $a$. 

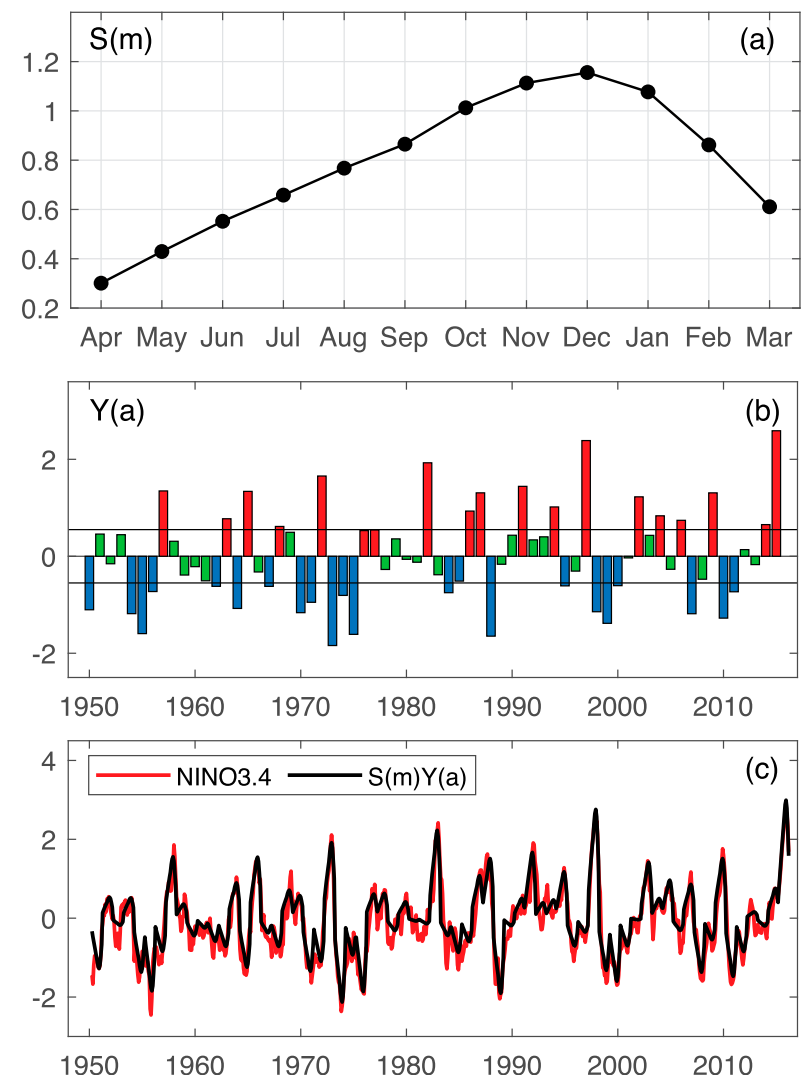

FIG. 2. Representation of the Niño-3.4 index $\left({ }^{\circ} \mathrm{C}\right)$ as the product of $S(m) Y(a)$, where $S(m)(m=1$ for April, $m=2$ for May, ..., $m=12$ for March) is the calendar-year structure function and $Y(a)$ $(a=1950,1951, \ldots, 2015)$ is the annual time series amplitude function. The product $S(m) Y(a)$ was determined as the first mode of an EOF analysis of the April, May, June, ..., February, March Niño time series. The first EOF mode represents $87.3 \%$ of the Niño-3.4 index variance. (a) The structure function $S(m)$. The structure function has been normalized so that $\sum_{m=1}^{12}[S(m)]^{2}=12$. (b) The annual amplitude function $Y(a)$. When $|S(m) Y(a)| \geq$ $0.55^{\circ} \mathrm{C}$ for at least 3 months of the year, the year is an El Niño year $(Y>0$, red) or a La Niña year $(Y<0$, blue). When $|S(m) Y(a)|<$ $0.55^{\circ} \mathrm{C}$, the year is neutral (green). (c) Niño-3.4 (black line) and $S(m) Y(a)$ (red line). The correlation between these two series is $\left[r=0.93, r_{\text {crit }}(95 \%)=0.25\right]$. The value in the bracket is the critical correlation coefficient at the 95\% level based on Ebisuzaki (1997). Here the Niño-3.4 index is from https://www.cpc.ncep.noaa.gov/ products/analysis_monitoring/ensostuff/detrend.nino34.ascii.txt, and the monthly anomaly is calculated by removing the mean of January 1993-December 2016.

Specifically, once $Y(a)$ is known for a given year, we can expect that Niño-3.4 will be extremely persistent and easy to predict; according to the right-hand side (RHS) of (1), within a given El Niño year from April of one year to March of the following year the correlation between the monthly calendar Niño-3.4 time series should be one. If there were a completely random relationship between $Y(a)$ and $Y(a+1)$, then the correlation between any two time series across the March time series

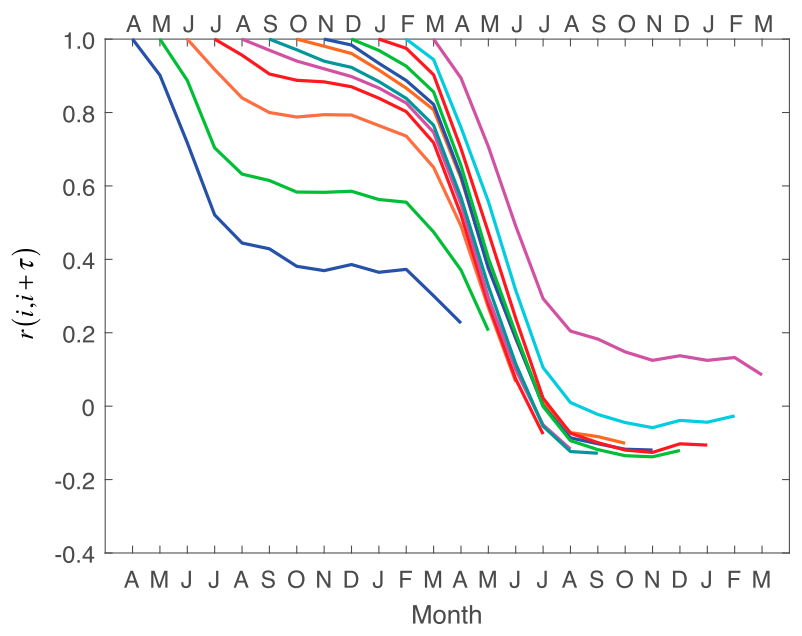

FIG. 3. Correlation curves for each calendar month, based on data from January 1950 to December 2016. Each curve begins with $r=1$ and corresponds to the correlation of a given month's Niño3.4 time series with itself. The next 12 points on each curve correspond to the correlation of that month's Niño-3.4 time series with the Niño-3.4 time series of each of the next 12 successive months. Adapted and updated from Clarke (2008). Here the Niño-3.4 index is from https://www.cpc.ncep.noaa.gov/products/analysis_monitoring/ ensostuff/detrend.nino34.ascii.txt, and the monthly anomaly is calculated by removing the mean of January 1993-December 2016.

of year $a$ to any calendar time series in year $a+1$ would be zero. For example, if we were to correlate the July values of Niño-3.4 with the time series in February of the following calendar year the correlation would be one (since both time series are in the same El Niño year $a$ ), but the correlation between the July time series and the April, May, or June time series of the following year would be zero (since these time series are in El Niño year $a+1)$. In practice the correlation of the Niño3.4 July series with itself is one (see the first point on the red second "J" curve in Fig. 3) and then decreases only slightly in the following months until April, May, and June when it plummets to be near zero. Consistent with this, the 11 other curves that begin with calendar months other than July are nearly horizontal and near 1 from wherever they begin until they reach April and then they plummet (as seen graphically in Fig. 3).

WWV has the remarkable ability to overcome this persistence barrier and provide a way to predict El Niño and La Niña statistically. For example, whereas Fig. 3 suggests that in January we cannot statistically determine Niño-3.4 six months later, the January curve in the top left panel of Fig. 4 (an update of Fig. 4 of Clarke and Van Gorder 2003) shows that the January WWV time series leads Niño-3.4 by about 16 months with a correlation greater than 0.5 . The top two panels of the figure show that similar predictive capability is available for all the calendar months February-June. 

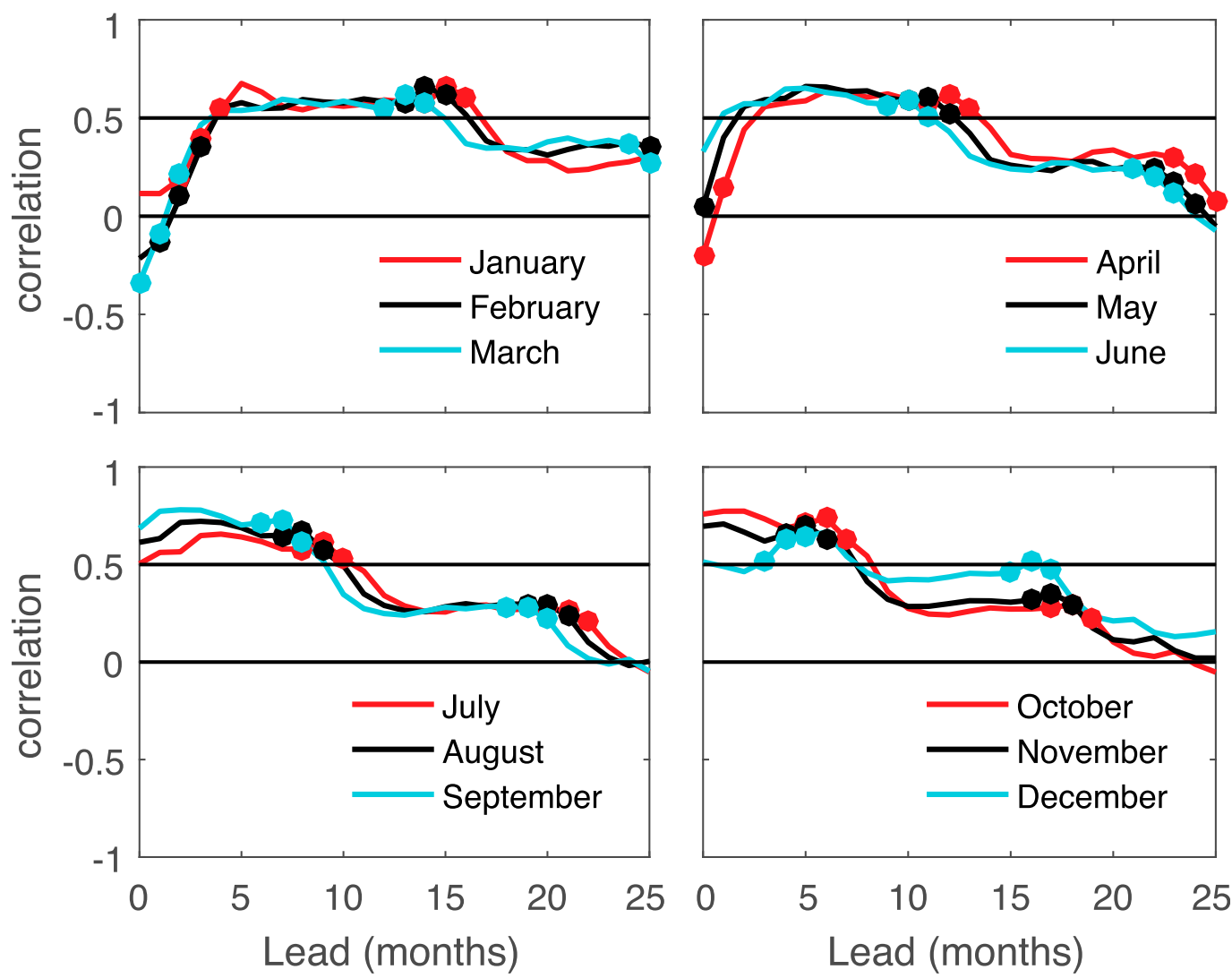

FIG. 4. Lead correlations of WWV $(t)$ for each calendar month with Niño-3.4 $(t+$ lead $)$ for the period January 1980-December 2016. A positive lead corresponds to WWV leading Niño-3.4. The first month in each quarter is a red line, the second is black, and the third is cyan. The Niño-3.4 is downloaded from https://www.cpc.ncep.noaa.gov/ products/analysis_monitoring/ensostuff/detrend.nino34.ascii.txt. The WWV is available at https://www.pmel.noaa.gov/ tao/wwv/data/. Both time series are from January 1980 to December 2016, and the monthly anomaly is calculated by removing the mean of January 1993-December 2016. To indicate the position of the persistence barrier on each plot, the dots on each time series correspond to the months March, April, and May.

But why is WWV able to predict Niño-3.4 and hence ENSO variability? Jin (1997a,b) first suggested theoretically why El Niño/La Niña should be linked with WWV, and hence that recharge (WWV $>0$ ) should lead El Niño and discharge $(W W V<0)$ should lead La Niña. Jin's (1997a) conceptual model, which is deduced from the "two-strip" coupled model of Jin (1997b), assumes that on ENSO time scales the zonal acceleration can be omitted from the zonal momentum balance, that is, that the zonal pressure gradient along the equator balances the zonal wind stress forcing. But as we will show in section 4 , such a balance along the equator implies that WWV does not lead El Niño and La Niña.

Although there have been several theories relating El Niño/La Niña to the WWV (Jin 1997a,b; Clarke et al. 2007; Fedorov 2010; Clarke 2010; Thual et al. 2013; Neske and McGregor 2018), only recently (Zhang and Clarke 2017) has the direct linkage between the zonal equatorial flow and WWV begun to be appreciated. In this paper we will apply that relationship to understand the physics of why the WWV is a useful predictor of El Niño beyond the spring persistence barrier.

Several questions arise from the preceding work, and these will frame the structure of the rest of this paper.

1) The strong phase-locking to the seasonal cycle of El Niño in Figs. 2 and 3 and the seasonal phase-locking of the prediction of El Niño from WWV seen in Fig. 4 must be evident in the structure of Fig. 1. What does the phase-locked version of Fig. 1 look like?

2) What is the basic physics of why WWV is able to predict across the spring persistence barrier?

3) How does the mechanism in question 2 depend on El Niño and La Niña?

4) Why is WWV a better predictor during some decades than others (McPhaden 2012; Horii et al. 2012; Bunge and Clarke 2014)? 
In section 2 we address question 1 . To answer the second question requires more than one section. Our analysis will focus on the equator where the Coriolis parameter $f=0$. Therefore, in section 3 we first establish that an equatorial version $\mathrm{WWV}_{\mathrm{EQ}}$ of the $\mathrm{WWV}$ is the same statistically as the traditional $5^{\circ} \mathrm{S}-5^{\circ} \mathrm{N}$ WWV defined in the first paragraph of the introduction. We also demonstrate that zonally averaged equatorial sea level, adjusted for the influence of sea surface salinity (SSS), can also be used as a proxy for WWV. In section 4 we then demonstrate that the standard conceptual models of WWV (e.g., Jin 1997a; Clarke et al. 2007) have a serious deficiency. Specifically, they are both based on a zonal momentum equation that omits the zonal acceleration term. Mathematically we show that this results in a $W W V_{E Q}$ that does not lead El Niño and La Niña, that is, a theoretical $\mathrm{WWV}_{\mathrm{EQ}}$ that does not have WWV's key prediction property. Section 5 shows how this discrepancy can be addressed, and physically explains why WWV can predict El Niño past the spring persistence barrier. Thus, sections 2-5 address question 2. Questions 3 and 4 are addressed by sections 6 and 7 , and a final section 8 summarizes the main results.

\section{Seasonal phase-locking and asymmetry of El Niño and WWV}

As shown in Fig. 2, Niño-3.4 can be well approximated by a sequence of 1-yr events that begin in April of a given calendar year and end in March of the next. In our calculations we define a given year to be an El Niño year if for 3 or more months $S(m) Y(a) \geq 0.55^{\circ} \mathrm{C}$ and $S(m)$ $Y(a) \leq-0.55^{\circ} \mathrm{C}$ for a La Niña. The $S(m)$ spans two calendar years and we name the El Niño or La Niña the first of those years. For the data analyzed from January 1980 to December 2016, under our definition there have been 11 El Niños (1982, 1986, 1987, 1991, 1994, 1997, 2002, 2004, 2006, 2009, and 2015) and 12 La Niñas (1983, 1984, 1985, 1988, 1995, 1998, 1999, 2000, 2007, 2008, 2010, and 2011). These El Niño and La Niña years are nearly the same as those defined by the U.S. National Weather Service Climate Prediction Center (http:// ggweather.com/enso/oni.htm).

The phase diagrams in Fig. 5 are based on averages of El Niños and La Niñas since 1980. For example, the "El Niño" phase diagram in Fig. 5a shows the average values of the points (Niño-3.4, WWV) for each of the El Niño months April to March of the El Niño year [red, Year(0)], each of the 12 months before the El Niño year [blue, Year(-1)], and each of the 12 months after the El Niño year [green, Year(+1)]. In agreement with the past work of Meinen and McPhaden (2000) and
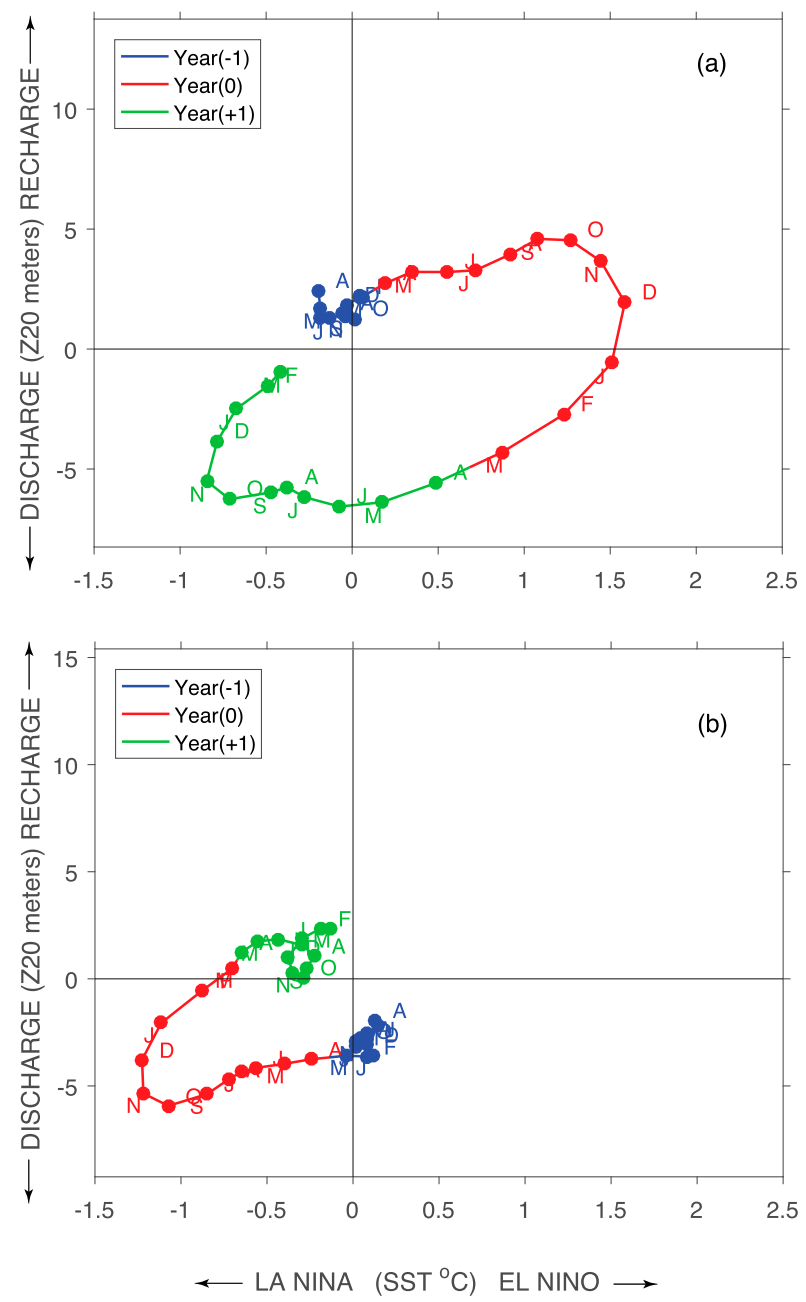

FIG. 5. Phase diagram for the average (a) El Niño and (b) La Niña events since 1980. Here we define El Niño (La Niña) based on Fig. 2 when $|S(m) Y(a)| \geq 0.55^{\circ} \mathrm{C}$ for at least 3 months of the year. In (a) Year(0) corresponds to the El Niño year, Year $(-1)$ to the year before the El Niño, and Year $(+1)$ the year after the El Niño year. (b) As in (a), but La Niña replaces El Niño.

Kessler (2002), the sequence of points in time is in a clockwise sense. In Year( $(-1)$ the points correspond to a small positive WWV ("recharge") and near zero Niño3.4, transitioning to a growing large positive El Niño that decays in February and March at the end of El Niño Year(0). The transition from Year(0) to Year(+1) occurs as Niño-3.4 is small and the WWV is negative and large in magnitude (large "discharge"). Consistent with the growth from April to December, and then decay seen in Fig. 2a, the green points in Fig. 5a show that a La Niña develops from April to December, and then decays. Year $(+1)$ ends in March in a state of weak La Niña with negligible WWV. Thus, if $Y(a)$ is positive corresponding to an El Niño, then $Y(a+1)$ tends to be negative. 
The lead correlations of January unfiltered WWV with unfiltered Niño-3.4 for the following months (see red curve in the top left panel of Fig. 4) show that January WWV is positively correlated at better than 0.5 for the following El Niño year (April-March) and even into April and May of the next El Niño year. This is consistent with a clockwise rotation of the phase diagram trajectory in Fig. 5a since a positive lead correlation implies WWV $>0$ precedes an El Niño and WWV $<0$ precedes a La Niña.

The corresponding "La Niña" phase diagram shown in Fig. 5b, based on the La Niñas since 1980, shows a very different behavior for Year(-1), Year(0), and Year(+1). Instead of moving clockwise through three of the four quadrants, the La Niña trace essentially only moves clockwise during Year(0) and stays in the two left quadrants. The trace ends as a weak recharge/La Niña with no hint of a following El Niño. Thus in this case if $Y(a)$ is negative corresponding to a La Niña, then $Y(a+1)$ is not of opposite sign as it is in the El Niño case, but is weak and of the same sign.

Note that Figs. 5a and 5b suggest that while an El Niño tends to be followed next year by a La Niña [or at least $Y(a+1)$ of opposite sign], a La Niña tends to be followed next year by another La Niña [or at least $Y(a+1)$ of the same sign]. This asymmetry is consistent with the previous asymmetry work of Larkin and Harrison (2002) and Okumura and Deser (2010). Their analyses did not include the WWV, but did find both an El Niño and a La Niña tend to be followed by a La Niña. In appendix A we explore this further quantitatively in the phase-locked context of this paper since 1873 using the long Niño-3.4 dataset constructed by Bunge and Clarke (2009). Their monthly Niño-3.4 dataset is validated by three observationally independent datasets that are well-correlated to Niño-3.4 because they are linked by simple physics. Even when global warming is taken into account, the analysis in appendix A verifies the tendency for both El Niño and La Niña to be followed by negative Niño-3.4 the following ENSO year.

This result raises another issue. Since negative Niño3.4 can be preceded by an El Niño or a La Niña, it is not surprising in Fig. $5 b$ that the Year $(-1)$ before a La Niña is on average neutral. Thus, Fig. $5 b$ is misleading in the sense that it gives the impression that typically Year $(-1)$ before a La Niña is neutral rather than Year $(-1)$ being either an El Niño or La Niña. In fact since 1980 a neutral Year(-1) before a La Niña is not typical; none of the 12 La Niñas is preceded by a neutral year, 6 are preceded by an El Niño year, and 6 by a La Niña year. Figure 6 shows phase diagrams corresponding to the separate cases when a Year(0) La Niña
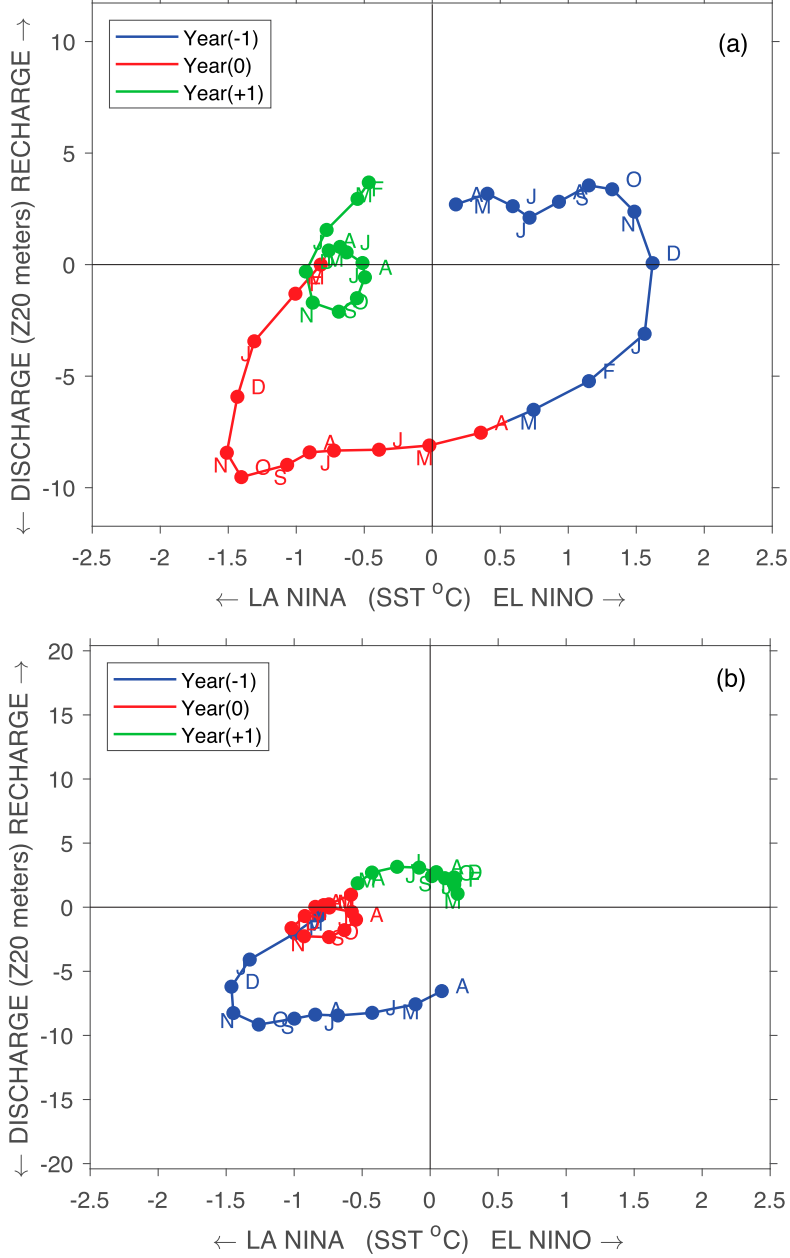

FIG. 6. Phase diagram as for the La Niña Year(0) case in Fig. 5b but now subdivided into the cases (a) when the Year(-1) corresponds to an El Niño and (b) when the Year $(-1)$ case corresponds to a La Niña. Since 1980 there have been no cases when a Year(0) La Niña was preceded by a neutral Year $(-1)$, six cases $(1983,1988$, $1995,1998,2007$, and 2010) when La Niña Year(0) is preceded by an El Niño Year(-1) and six cases (1984, 1985, 1999, 2000, 2008, and 2011) when it is preceded by La Niña Year( -1$)$.

is either preceded by an El Niño (Fig. 6a) or La Niña (Fig. 6b).

The asymmetric behavior seen in Fig. 5 suggests that WWV may have different predictive capability depending on whether WWV is positive or negative. Figure 7, which is analogous to Fig. 4 except that separate calculations are done for WWV discharge and recharge, enables us to assess the relative merits of discharge and recharge as La Niña/El Niño predictors. The lead correlations in each case are calculated using a conditional correlation coefficient $r_{*}$ analogous to that used in appendix A. Specifically, for the monthly unfiltered WWV $<0$ and monthly unfiltered Niño-3.4 we calculate the statistic 

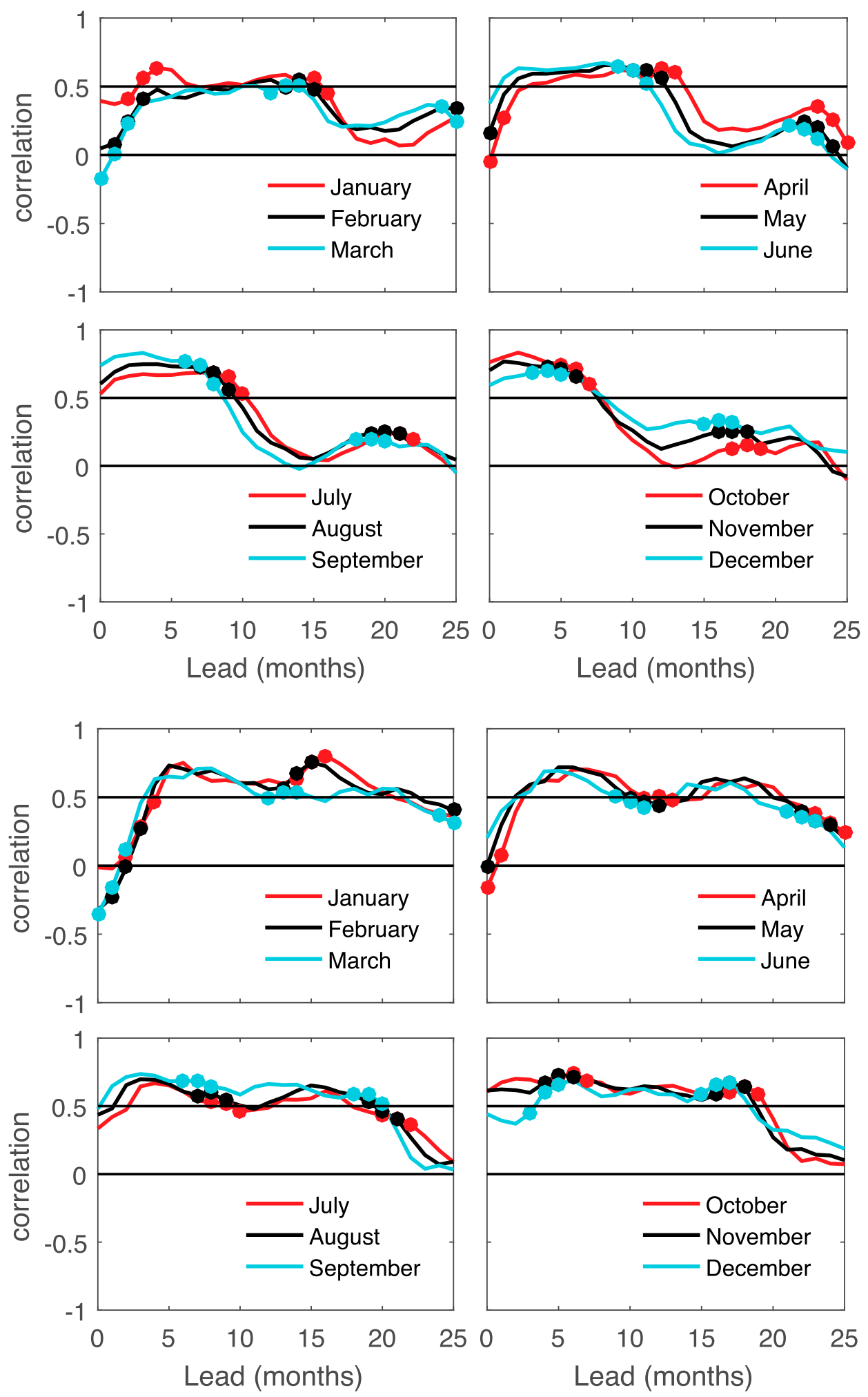

FIG. 7. Analogous lead correlations to Fig. 4 except that the sign of WWV $(t)$ is taken into account. The top four panels correspond to correlations $r_{*}$ [see (2)] of WWV $(t)$ with Niño-3.4 $(t+$ lead $)$ for WWV $(t)>$ 0 and the bottom four panels for $\mathrm{WWV}(t)<0$. 


$$
\begin{aligned}
r_{*}= & \sum_{\text {all } \mathrm{WWV}<0} \operatorname{WWV}(t) \operatorname{Niño3} .4(t+\text { lead }) / \\
& \left\{\sum_{\text {all WWV }<0}[\mathrm{WWV}(t)]^{2}\right\}^{1 / 2} \\
& \times\left\{\sum_{\text {all } \mathrm{WWV}<0}[\operatorname{Niño3} .4(t+\text { lead })]^{2}\right\}^{1 / 2} .
\end{aligned}
$$

Notice that $r_{*}$ differs from the usual correlation $r$ in that $\mathrm{WWV}(t)$ does not have a zero mean since it is negative. However, $r_{*}$ has typical linear correlation properties in the sense that if Niño-3.4 $(t+$ lead $)=\alpha \mathrm{WWV}(t)$ then $r_{*}$ would be 1 for $\alpha>0$ and -1 for $\alpha<0$.

Comparison of the results in Fig. 7 suggests that WWV $<0$ can be used to predict Niño-3.4 with much greater lead time than WWV $>0$ (top four panels); in particular, when WWV is less than zero the next El Niño/La Niña year can be predicted from July with a correlation better than 0.5 up to 18 months in advance, but for WWV $>0$ the lead for correlation better than 0.5 is reduced to 11 months (cf. the correlations from July onward for the WWV $<0$ and WWV $>0$ cases in Fig. 7). In other words, WWV $<0$ in July can be used to predict past the persistence barrier and through to the next El Niño/La Niña year whereas in July WWV $>0$ cannot. Figure 7 shows that when WWV $<0$, all months following July are able to predict past the persistence barrier, but that when WWV $>0$ and for a correlation better than 0.5 , we have to wait until January before WWV $>0$ can be used to predict past the persistence barrier.

\section{Equivalence of $W W V, W W V_{E Q}$, and adjusted zonally averaged equatorial sea level}

WWV is traditionally defined as an average from $5^{\circ} \mathrm{S}$ to $5^{\circ} \mathrm{N}$ across the Pacific (see the first paragraph of section 1). However, it will be convenient to base our analysis at the equator, and so in this section we first establish that $\mathrm{WWV}$ and its equatorial version $\mathrm{WWV} \mathrm{EQ}_{\mathrm{EQ}}$ are essentially equivalent indices. $\mathrm{WWV}_{\mathrm{EQ}}$ is defined as the monthly anomalous depth of the $20^{\circ} \mathrm{C}$ isotherm averaged along the equator from $120^{\circ} \mathrm{E}$ to $80^{\circ} \mathrm{W}$. We will also show that WWV is also equivalent to $\overline{\eta_{\text {thermocline}}}$, where $\overline{\eta_{\text {thermocline }}}$ is a monthly zonal average along the equator of monthly anomalous satellite sea surface height (SSH) with an adjustment for the influence of SSS (see the discussion below).

Figure 8 shows that up to $2010 \mathrm{WWV}$ and $\mathrm{WWV} \mathrm{EQ}_{\mathrm{EQ}}$ are maximally and highly correlated at zero lag, and so are essentially equivalent time series. For a few years after 2010 the $20^{\circ} \mathrm{C}$ isotherm depth along the equator did

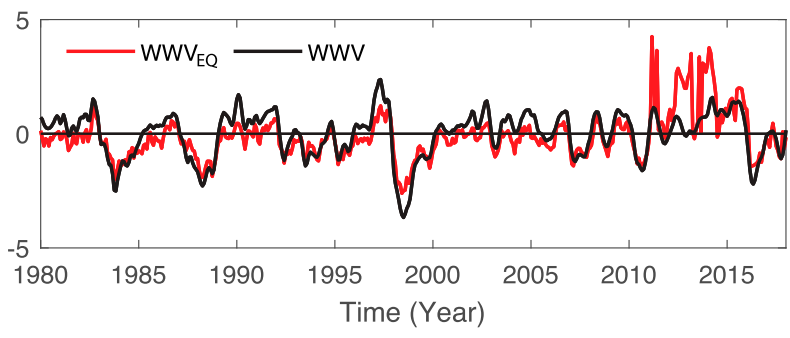

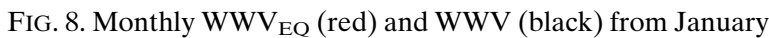
1980 to January 2018. Both time series have been normalized by their standard deviations which were $16.7 \mathrm{~m}$ for $\mathrm{WWV}_{\mathrm{EQ}}$ and $5.4 \mathrm{~m}$ for WWV. From January 1980 to December 2010 the time series are highly and maximally correlated at zero lag $\left[r=0.94, r_{\text {crit }}\right.$ $(95 \%)=0.34]$. WWV $\mathrm{EQ}_{\mathrm{EQ}}$ and $\mathrm{WWV}$ differ for a few years following 2010 because too few equatorial $20^{\circ} \mathrm{C}$ depth observations were available then.

not have enough data to calculate monthly values of $\mathrm{WWV}_{\mathrm{EQ}}$ accurately (see Fig. 8). A backup estimate for the subsurface WWV and $\mathrm{WWV}_{\mathrm{EQ}}$ indices can be provided by satellite SSH and SSS data as follows.

As has been noted elsewhere (see, e.g., Clarke 2008, p. 46), because ENSO time-scale currents and therefore pressure fluctuations beneath the thermocline are small compared to those above, to a first approximation the mass above the bottom of the thermocline does not change. Therefore we can expect a mass increase above the bottom of the thermocline due to increased sea level to be compensated by a mass decrease due to a much thicker slightly less dense layer associated with the thermocline depth. In other words, we expect the monthly sea level anomalies $\eta$ to be proportional to D20, the depth of the $20^{\circ} \mathrm{C}$ isotherm, a proxy for the thermocline depth and water column thickness above the thermocline. High correlations between monthly sea level anomalies and D20 anomalies consistent with this physics usually occur, but they are lower in the western equatorial Pacific from about $165^{\circ} \mathrm{E}$ to $170^{\circ} \mathrm{W}$ [see our Table 1 and the top panel of Fig. 4 of Bunge and Clarke (2014)]. Our Table 1 correlations are based on monthly anomalies of satelliteestimated SSH available from the Archiving, Validation, and Interpretation of Satellite Oceanographic (AVISO) dataset (http://www.aviso.oceanobs.com) and monthly anomalies of D20 from TAO/TRITON in situ equatorial Pacific station data (http://www.pmel.noaa.gov/tao/ disdelframes/main.html).

The lower-correlation equatorial region between about $165^{\circ} \mathrm{E}$ and $170^{\circ} \mathrm{W}$ is influenced by an interannual shallow (50-70 $\mathrm{m}$ deep) freshwater jet that is fundamental to ENSO dynamics (Zhang and Clarke 2015). Because of the jet, the monthly anomalous sea level in this region has a contribution not only from thermocline variability, but also from the dynamic height $\zeta_{T F}$ associated with the low-salinity jet. Since we are interested in the WWV 
TABLE 1. At TAO/TRITON stations along the equator across the Pacific, the correlation between the monthly anomalous $20^{\circ} \mathrm{C}$ isotherm depth (D20) and the monthly anomalous satellite SSH (column 2), and between D20 and $\eta_{\text {thermocline }}$ sea level (column 3), with $\eta_{\text {thermocline }}$ being more representative of D20 [see (3) and the discussion in the text]. The correlation in parentheses is $r_{\text {crit }}(95 \%)$. The time periods used to calculate the correlations are shown in column 4.

\begin{tabular}{|c|c|c|c|}
\hline Station & SSH and D20 & $\eta_{\text {thermocline }}$ and D20 & Time period \\
\hline $0^{\circ}, 147^{\circ} \mathrm{E}$ & $0.80(0.39)$ & $0.88(0.46)$ & March 1999-December 2010 \\
\hline $0^{\circ}, 156^{\circ} \mathrm{E}$ & $0.80(0.40)$ & $0.84(0.40)$ & January 1993-December 2010 \\
\hline $0^{\circ}, 165^{\circ} \mathrm{E}$ & $0.61(0.36)$ & $0.58(0.36)$ & January 1993-December 2010 \\
\hline $0^{\circ}, 180^{\circ}$ & $0.50(0.33)$ & $0.83(0.35)$ & December 1995-December 2010 \\
\hline $0^{\circ}, 170^{\circ} \mathrm{W}$ & $0.55(0.33)$ & $0.78(0.34)$ & July 1995-December 2010 \\
\hline $0^{\circ}, 155^{\circ} \mathrm{W}$ & $0.86(0.44)$ & $0.88(0.42)$ & November 2000-December 2010 \\
\hline $0^{\circ}, 140^{\circ} \mathrm{W}$ & $0.88(0.38)$ & $0.90(0.38)$ & January 1993-June 2007 \\
\hline $0^{\circ}, 125^{\circ} \mathrm{W}$ & $0.90(0.43)$ & $0.91(0.41)$ & April 1997-December 2010 \\
\hline $0^{\circ}, 110^{\circ} \mathrm{W}$ & $0.91(0.37)$ & $0.91(0.37)$ & September 1997-December 2010 \\
\hline $0^{\circ}, 95^{\circ} \mathrm{W}$ & $0.86(0.34)$ & $0.85(0.34)$ & November 1998-December 2010 \\
\hline
\end{tabular}

signal, we remove the effect of the freshwater jet dynamic height and write the sea level $\eta_{\text {thermocline }}$ due to anomalous thermocline displacement as

$$
\eta_{\text {thermocline }}=\mathrm{SSH}-\zeta_{T F} .
$$

The anomalous monthly dynamic height $\zeta_{T F}$ was estimated, following Zhang and Clarke (2015), as

$$
\zeta_{T F}=\left(\beta_{S}\right)(\mathrm{ILD})\left(\mathrm{SSS}^{\prime}\right)-\left(\alpha_{T}\right)(\mathrm{ILD})\left(\mathrm{SST}^{\prime}\right),
$$

where $\beta_{S}$ is the salinity contraction coefficient, ILD is the time-averaged isothermal layer depth, SSS $^{\prime}$ is the monthly sea surface salinity anomaly, $\alpha_{T}$ is the thermal expansion coefficient, and $\mathrm{SST}^{\prime}$ the monthly SST anomaly.

Except for the slight correlation decrease at $165^{\circ} \mathrm{E}$, Table 1 shows that, as we might expect, the correlation between D20 and $\eta_{\text {thermocline }}$ is greater than that between $\mathrm{D} 20$ and SSH for the equatorial longitudes $147^{\circ} \mathrm{E}-$ $170^{\circ} \mathrm{W}$ where the freshwater jet is most active. As a result $\mathrm{WWV}_{\mathrm{EQ}}$ is better related to a similar zonal equatorial average of $\eta_{\text {thermocline }}$ (denoted $\overline{\eta_{\text {thermocline }}}$ ) than a similar zonal average of SSH $(\overline{\mathrm{SSH}})$. Specifically, $\mathrm{WWV}_{\mathrm{EQ}}$ and $\bar{\eta}_{\text {thermocline }}$ are maximally correlated at zero lead $\left[r=0.95, r_{\text {crit }}(95 \%)=0.45\right]$, but $\mathrm{WWV}_{\mathrm{EQ}}$ and $\overline{\mathrm{SSH}}$ are maximally correlated when $\mathrm{WWV}_{\mathrm{EQ}}$ leads $\overline{\mathrm{SSH}}$ by two months $\left[r=0.73, r_{\text {crit }}(95 \%)=0.45\right]$, the correlation falling to $r=0.69\left[r_{\text {crit }}(95 \%)=0.44\right]$ at zero lead. Here and elsewhere $r_{\text {crit }}(95 \%)$ is the critical correlation coefficient at the $95 \%$ confidence level based on Ebisuzaki (1997).

Note that since $\mathrm{WWV}_{\mathrm{EQ}}$ leads $\overline{\mathrm{SSH}}$ by 2 months, $\mathrm{WWV}_{\mathrm{EQ}}$ is a better predictor of Niño-3.4 than $\overline{\mathrm{SSH}}$. The physical reason for this is that SSH includes $\zeta_{T F}$, and, as shown by Zhang and Clarke (2015), $\zeta_{T F}$ is in phase with the anomalous zonal equatorial wind stress and Niño3.4. Consequently, the presence of $\zeta_{T F}$ in SSH makes
$\overline{\mathrm{SSH}}$ more in phase with Niño-3.4 and not as good a predictor of it.

As might be expected from the equivalence of WWV, $\mathrm{WWV}_{\mathrm{EQ}}$, and $\overline{\eta_{\text {thermocline }}}, \mathrm{WWV}$ and $\overline{\eta_{\text {thermocline }}}$ are maximally correlated $\left[r=0.87, r_{\text {crit }}(95 \%)=0.38\right]$ at zero lead and therefore

$$
\mathrm{WWV}=122 \overline{\eta_{\text {thermocline }}},
$$

where the ratio of the standard deviation's regression coefficient (Clarke and Van Gorder 2013) in (5) is dimensionless because WWV here is defined as an average depth (see the first paragraph of section 1). The relationship (5) may be of practical use as it only uses SSH, SST, and SSS data along the equator so subsurface data are not essential.

\section{A flaw in the physics of the recharge/discharge theory of EI Niño}

Section 3 has established observationally that $\mathrm{WWV}_{\mathrm{EQ}}$ and $\overline{\eta_{\text {thermocline }}}$ are proxies for the WWV. In this section we will show that, under the assumptions made by the generally accepted conceptual model of the recharge/ discharge theory of El Niño/La Niña (see Jin 1997a; Clarke et al. 2007), $\mathrm{WWV}_{\mathrm{EQ}}, \overline{\eta_{\text {thermocline }}}$, and therefore WWV do not lead Niño-3.4. There is thus a flaw in the generally accepted recharge/discharge physics since it cannot reproduce the key property of WWV, namely that it can be used to predict El Niño/La Niña.

As in Jin (1997a), consider the simple case of a twodensity layer linear ocean model with its lower layer at rest. For such a "1.5-layer model," the sea level $\eta$ and density downward interface displacement $h$ are proportional to one another. Analogous with section 3, model $\eta$ and $h$ are proxies for $\eta_{\text {thermocline }}$ and anomalous $20^{\circ} \mathrm{C}$ isotherm depth respectively. It thus follows from the results of section 3 that $\bar{\eta}$, the zonal average along 
the equator of the model equatorial sea level, is a proxy for $\mathrm{WWV}_{\mathrm{EQ}}$ and $\mathrm{WWV}$.

In our notation the large zonal scale, low-frequency linear ocean model equations (2.1) of Jin (1997b) are

$$
\begin{aligned}
(\partial / \partial t+\lambda) u-f v & =-g \eta_{x}+\tau^{x} /\left(\rho_{1} H_{1}\right), \\
f u & =-g \eta_{y}, \quad \text { and } \\
g c^{-2}(\partial / \partial t+\lambda) \eta+u_{x}+v_{y} & =0 .
\end{aligned}
$$

In (6)-(8) $x$ is the distance east of the western ocean boundary, $y$ the distance north of the equator, $t$ the time, $\lambda^{-1}$ the dissipation time scale of the large-scale flow, $u$ and $v$ the eastward and northward velocity components, $f=\beta y$ the Coriolis parameter, $\tau^{x}$ the eastward wind stress, $H_{1}$ the upper layer thickness, $g$ the acceleration due to gravity, $\rho_{1}$ the upper layer density, $\Delta \rho$ the (positive) density difference between the layers, $\varepsilon=\Delta \rho / \rho_{1}$, $c=\left(g \varepsilon H_{1}\right)^{1 / 2}$ the long internal gravity wave speed, and $\eta=\varepsilon h$.

Both the Jin (1997a) and Clarke et al. (2007) theories omit the zonal flow acceleration from the zonal equatorial momentum equation (6). Under this approximation (6) at the equator reduces to the quasi-steady "tilt" balance between zonal wind stress and zonal pressure gradient

$$
g \eta_{x}=\tau^{x} / \rho_{1} H_{1}
$$

If (9) is multiplied by $x / g$ and integrated from $x=0$ $\left(139.5^{\circ} \mathrm{E}\right)$ to the eastern equatorial ocean boundary $x=$ $L\left(82.5^{\circ} \mathrm{W}\right)$ then we have, after dividing by $L$,

$$
\int_{0}^{L}(x / L) \eta_{x} d x=\left(\rho_{1} H_{1} g\right)^{-1} \int_{0}^{L}(x / L) \tau^{x} d x .
$$

Upon integrating the left-hand side (LHS) of (10) by parts we obtain

$$
\bar{\eta}(t)=\eta_{E}-\left(\rho_{1} H_{1} g\right)^{-1} \int_{0}^{L}(x / L) \tau^{x} d x,
$$

where $\eta_{E}$ is $\eta$ at the eastern boundary $x=L$. As mentioned above the first term $\eta_{E}$ on the right hand side of (11) is proportional to the thermocline displacement in the eastern equatorial Pacific and hence to El Niño indices like Niño-3.4. For example, with $\eta_{E}$ represented as anomalous monthly satellite SSH on the equator at $82.5^{\circ} \mathrm{W}$, the correlation of $\eta_{E}$ with Niño-3.4 is $r=0.75$, $\left[r_{\text {crit }}(95 \%)=0.39\right]$ at zero lag (see Table 2, row 2, column 5) and is a maximum $(r=0.76)$ when $\eta_{E}$ leads by 1 month (see Table 2, row 5, column 2). The integral term on the RHS of (11) is strongly related to the zonal equatorial wind anomalies occurring during El Niño/ La Niña, and so is proportional to minus the Equatorial Southern Oscillation index (-ESOI) (Clarke and Lebedev 1996; Bunge and Clarke 2009) and Niño-3.4 (see Table 2, row 7, columns 2 and 3). Since both terms on the RHS of (11) are correlated with Niño-3.4 at near zero lag, the RHS itself is maximally correlated with Niño-3.4 at near-zero lag (see row 8 , column 2). This disagrees with a fundamental property of the rechargedischarge oscillator theory of El Niño, specifically that the WWV leads Niño-3.4 by several months (Meinen and McPhaden 2000). The lead of WWV over Niño-3.4 varies decadally (see section 7), but over the same January 1993-December 2016 period used for (11), WWV and $\overline{\eta_{\text {thermocline }}}$ still lead. Specifically, $\overline{\eta_{\text {thermocline }}}$ is maximally correlated with Niño-3.4 $\left[r=0.72, r_{\text {crit }}(95 \%)=\right.$ 0.38 ] when it leads Niño-3.4 by 3 months and WWV similarly leads Niño-3.4 $\left[r=0.66, r_{\text {crit }}(95 \%)=0.38\right]$ by 4 months.

\section{Zonal flow, WWV, and EI Niño prediction}

\section{a. Theory for $W W V$ being an El Niño predictor}

It is apparent from the previous section that if we are to understand why WWV can predict El Niño, zonal flow, and zonal acceleration must be included in (6). On the equator (6) reduces to

$$
g \eta_{x}=\tau^{x} / \rho_{1} H_{1}-(\partial / \partial t+\lambda) u .
$$

Integrating (12) in the same way we integrated (9) to obtain (11) we have

$$
\begin{aligned}
\bar{\eta}(t)= & \eta_{E}(t)-\int_{0}^{L}(x / L) \tau^{x} /\left(\rho_{1} H_{1} g\right) d x+g^{-1} \\
& \times \int_{0}^{L}(x / L)(\partial / \partial t+\lambda) u d x .
\end{aligned}
$$

As mentioned above, the first two terms on the RHS of (13) are in phase and proportional to Niño-3.4. It follows that the lead that $\bar{\eta}, \bar{h}$, and the WWV have over Niño-3.4 is due to the zonal flow acceleration term in (13). We verified this by lag correlating monthly Niño-3.4 with the RHS of (13) using AVISO sea level and OSCAR currents from February 1993 to November 2016. When the RHS of (13) included the zonal acceleration term, it led Niño-3.4 by 3 months $\left\{\max r=0.53\left[r_{\text {crit }}(95 \%)=0.27\right]\right\}$ and when it did not include the zonal acceleration term it led Niño-3.4 by 0 months $\left\{\max r=0.44\left[r_{\text {crit }}(95 \%)=\right.\right.$ $0.23]\}$.

Note that $u_{t}$ in (13) adjusts the ocean back to a quasisteady balance, so in this way $\bar{\eta}, \bar{h}$, and consequently the 


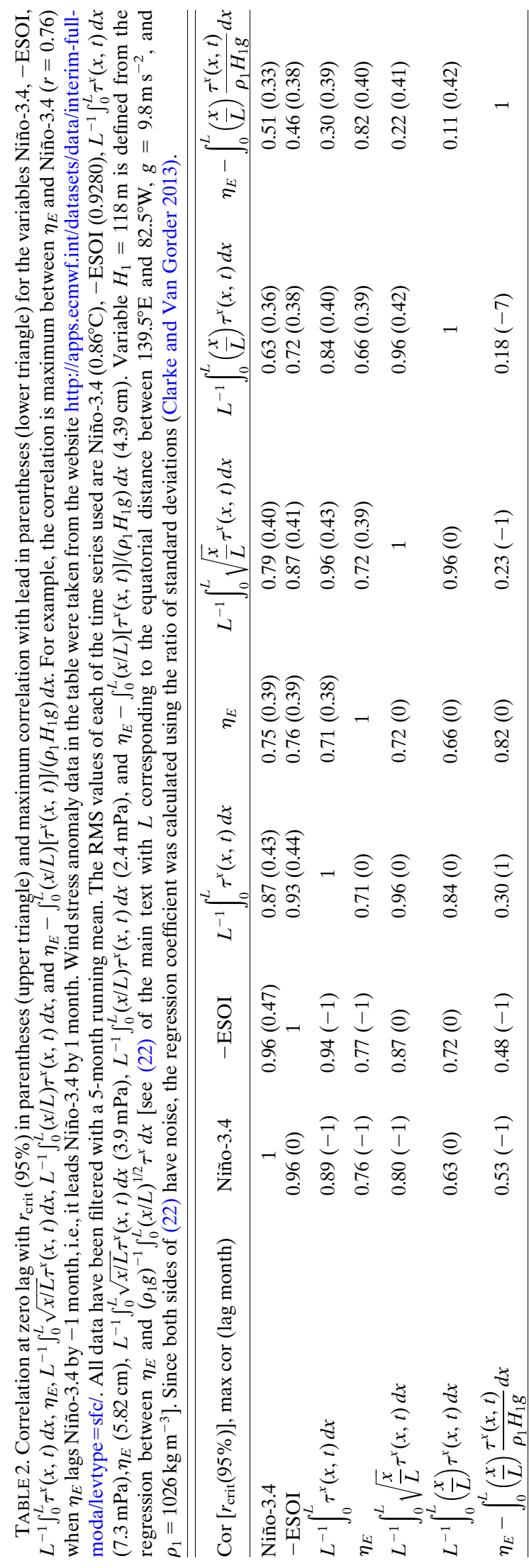

WWV are strongly associated with a "nonequilibrium" mode (Bunge and Clarke 2014). From (13) we can understand why WWV is an El Niño predictor if we can understand why the nonequilibrium zonal acceleration term on the RHS of (13) leads El Niño.

The zonal equatorial acceleration integral across the Pacific in (13) is weighted toward the eastern equatorial Pacific because of the factor $x / L$ in the integrand. Observations (Zhang and Clarke 2017) show that $u$ leads El Niño in this region. Since $(\partial / \partial t+\lambda) u$ leads $u$, and $u$ leads El Niño, it is no wonder that in (13) the nonequilibrium integral involving $(\partial / \partial t+\lambda) u$ is essential to $\bar{\eta}$ leading El Niño. But why, physically, should eastern equatorial Pacific $u$ lead El Niño? An explanation of this physics has recently been offered by Zhang and Clarke (2017), and this explanation in the context of some other previous results is briefly summarized below.

Zonal interannual equatorial wind anomalies are weak in the eastern equatorial Pacific (see, e.g., Fig. 9), and in this explanation of the basic physics they will be taken to be negligible. The incoming energy to the eastern boundary is then the sum of an incident equatorial Kelvin wave and a large number of reflected equatorial Rossby waves. At interannual and lower frequencies the eastern ocean boundary, especially at the low latitudes of interest $\left(10^{\circ} \mathrm{S}-10^{\circ} \mathrm{N}\right)$, acts dynamically like a meridional wall (Clarke 1992). For such a boundary, the incident equatorial Kelvin wave and the reflected equatorial Rossby waves can be summed (Cane and Moore 1981). The analytical solution shows that near enough to the boundary and at low enough frequency $\omega$ and long enough dissipation time scale $\lambda^{-1}$ such that $\left(\omega^{2}+\lambda^{2}\right)(L-x)^{2} /\left(c^{2}\right) \ll 1$, the sum is in the form of a long, damped, westward propagating Rossby wave (Clarke 1983; see also appendix B) with westward propagation speed

$$
\gamma=\beta c^{2} / f^{2} .
$$

At El Niño frequencies in the eastern Pacific region of negligible forcing east of $140^{\circ} \mathrm{W}$ (Fig. 9) this long Rossby wave solution is valid. For example, for the interannual frequency $\omega=2 \pi / 3.5$ years, distance of $140^{\circ} \mathrm{W}$ from the eastern boundary $L-x=6600 \mathrm{~km}$, dissipation time scale $\lambda^{-1}=3$ months, and $c=2.5 \mathrm{~m} \mathrm{~s}^{-1}$, the error $\left(\omega^{2}+\right.$ $\left.\lambda^{2}\right)(L-x)^{2} /\left(c^{2}\right)=13 \%$, small even when $L-x$ is largest at $140^{\circ} \mathrm{W}$. The long Rossby waves are nondispersive and so the solution can be written [see, e.g., Zhang and Clarke (2017) or appendix B]

$$
\eta(x, y, t)=\exp [\lambda(x-L) / \gamma] \eta_{E}[t+(x-L) / \gamma] .
$$

At the eastern boundary $u=0$, and this is consistent with (15), since for $x=L$ the sea level $\eta=\eta_{E}(t)$ is spatially 

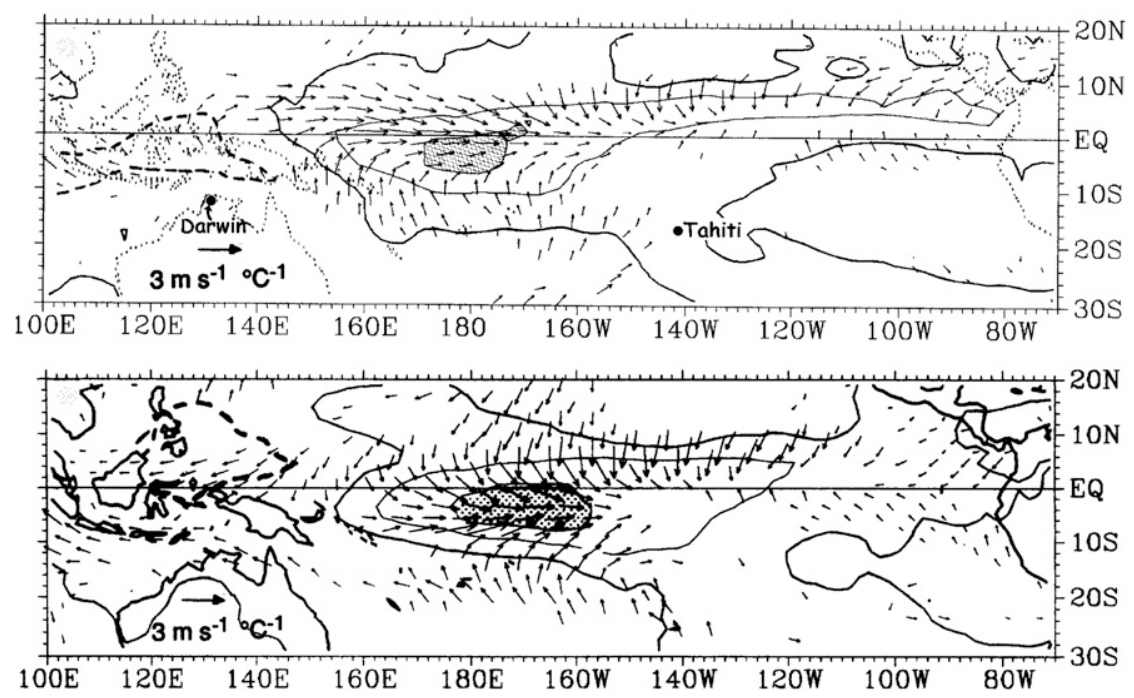

FIG. 9. (top) Regression of July-November surface wind (arrows) and outgoing longwave radiation (OLR) onto an equatorial SST index (July-November SST averaged over $6^{\circ} \mathrm{S}-6^{\circ} \mathrm{N}$, $180^{\circ}-80^{\circ} \mathrm{W}$ ). Wind vectors are only shown for those grid points whose $u$ or $v$ correlations with the SST index exceed 0.4 in absolute value. The OLR contour interval is $10 \mathrm{~W} \mathrm{~m}^{-2}{ }^{\circ} \mathrm{C}^{-1}$ of the SST index. The zero contour is darkened, and the positive contour is dashed. Values $<-20 \mathrm{~W} \mathrm{~m}^{-2}{ }^{\circ} \mathrm{C}^{-1}$ are shaded. The wind regressions are based on the period 1946-85 and the OLR regression on 1974-89 (1978 missing). (bottom) As in the top panel, but for December-February. [Redrawn from Deser and Wallace (1990).]

constant and so the geostrophic flow is zero. Note that this result implies that if we are to interpret the flow and the dynamics at El Niño frequencies it is better to think in terms of (15) rather than the individual equatorial Kelvin and many reflected equatorial Rossby waves making up the sum described by (15).

Seaward from the boundary, the strong variation of $\gamma=\beta c^{2} / f^{2}$ with latitude results in a meridional sea level gradient and

$$
u=-g \eta_{y} / f=2(L-x) g c^{-2}\left(\eta_{t}+\lambda \eta\right) .
$$

It follows that from (14) and (15) on the equator that $\eta=$ $\eta_{E}$, so in the eastern equatorial Pacific (16) can also be approximately written

$$
u=2(L-x) g c^{-2}\left(\eta_{E t}+\lambda \eta_{E}\right) .
$$

At ENSO frequencies $\omega$, the Taylor series expansion

$$
\eta_{E}(t+1 / \lambda)=\eta_{E}(t)+\lambda^{-1} \eta_{E t}(t)+\cdots
$$

shows that, with small error $\omega^{2} / 2 \lambda^{2}(10 \%$ for the $\omega$ and $\lambda$ used above), (17) can be written

$$
u(x, 0, t)=2(L-x) g c^{-2} \lambda \eta_{E}(t+1 / \lambda),
$$

that is, $u$ leads $\eta_{E}$ by approximately $\lambda^{-1}$. An analysis of observations by Zhang and Clarke (2017) showed (see their Table 1) that in the eastern Pacific surface equatorial $u$ leads eastern equatorial sea level by 3 months. Thus, (19) with $\lambda^{-1}=3$ months is consistent with the observations. Since $(\partial / \partial t+\lambda) u$ leads $u$, and eastern equatorial Pacific zonal current $u(x, 0, t)$ leads $\eta_{E}$, it follows from (13) that $\bar{\eta}$ and WWV lead $\eta_{E}$ and El Niño indices. Because the WWV can predict across the boreal spring persistence barrier, and Niño-3.4 is highly persistent from June till February the following year (Fig. 3), WWV has long lead times and therefore is a useful ENSO predictor (see sections $5 \mathrm{c}$ and 6 ).

Zhang and Clarke (2017) have offered a physical explanation for the lead of $u$ and $\bar{\eta}$. Based on geostrophy and no net flow into the eastern boundary, $\eta$ is spatially constant at the boundary. Sea level propagates westward from the boundary as a long Rossby wave with a speed that decreases rapidly with increasing latitude. Thus at a longitude west of the boundary sea level nearer the equator leads sea level farther from the equator so that in the undamped case $(\lambda=0)$ the meridional gradient of $\eta$ is proportional to a time derivative. In the damped case $\eta_{y}$ is proportional to $(\partial / \partial t+\lambda) \eta$, and by (17) and (18) $u$ leads $\eta$ and equatorial $u$ leads $\eta_{E}$ and El Niño indices. By (13) WWV leads $u$. Thus recharge leads El Niño and discharge leads La Niña, that is, the trajectory of the Niño-3.4/WWV phase diagram should rotate clockwise as seen in Figs. 1 and 5.

We have shown that WWV's ability to predict El Niño is strongly tied to the eastern equatorial Pacific zonal 
momentum. But how does this equatorial zonal momentum cause a horizontal convergence of water $-\left(u_{x}+v_{y}\right)$ onto the equator and subsequent change of WWV? Equation (16) results from zonal flow blocked by the eastern boundary, and since equatorial $\eta$ is independent of $x$ it gives rise to the zonal equatorial convergence $-u_{x}=2 g c^{-2}(\partial / \partial t+\lambda) \eta$. Since this is twice $-\left(u_{x}+v_{y}\right)$ [see (8)], we see that the blocking of zonal equatorial momentum by the eastern boundary is the cause of the horizontal equatorial convergence.

\section{b. Comparison with Jin $(1997 a, b)$}

A reviewer asked us to provide a more detailed comparison of our analysis with the seminal Jin (1997a,b) recharge/El Niño model. We summarize the reviewer's helpful questions and our response here.

Question 1: Since the model of Jin (1997b) on which the conceptual model (Jin 1997a) is based includes a parameterized estimate of the zonal equatorial flow acceleration term, isn't zonal equatorial flow acceleration included in Jin (1997b)? By choosing (in our notation) $\lambda^{-1}=30$ months [see the right-hand column of p. 831 of Jin (1997b) showing $\varepsilon_{m}=\lambda$ and $\varepsilon_{m}^{-1}=2.5$ years], Jin's zonal momentum acceleration contributes negligibly to the zonal equatorial balance, and enables him to use the equivalent of (9) in his conceptual recharge model [see Eq. (2.1) of Jin (1997a)]. As shown above, based on observed $u$, we expect $\lambda^{-1} \approx 3$ months, about 10 times Jin's value, and (9) is not valid by itself.

Question 2: But if WWV does not lead El Niño when Jin effectively assumes that the zonal flow acceleration is negligible, why does Jin's recharge model oscillate? The zonal equatorial tilt balance (9) integrated from $x=0$ to $x=L$ gives, analogously to (2.1) of Jin (1997a),

$$
\eta_{W}=\eta_{E}-\int_{0}^{L} \tau^{x} /\left(\rho_{1} H_{1} g\right) d x
$$

Table 2 (row 5, column 4) shows that since $\eta_{E}$ is in phase with $\int_{0}^{L} \tau^{x} /\left(\rho_{1} H_{1} g\right) d x$ and observed to be smaller in magnitude, (20) indicates that $\eta_{W}$ and $h_{W}$ should be equal to a negative constant times $\int_{0}^{L} \tau^{x} d x$. But a key component of Jin's recharge oscillator is the parameterized western boundary condition (2.3) of Jin (1997a). It is of the form

$$
d h_{W} / d t+R h_{W}=-\alpha_{*} \int_{0}^{L} \tau^{x} d x
$$

with $R^{-1}=8$ months and $\alpha_{*}$ a positive constant. At ENSO frequencies $\omega \sim 2 \pi / 42$ months, $h_{W}$ is not in phase with $-\int_{0}^{L} \tau^{x} d x$ since $d h_{W} / d t$ is comparable to $R h_{W}$. Therefore, it seems that Jin's recharge oscillation depends on a western boundary condition that is inconsistent with his tilt assumption [(2.1) of Jin 1997a].

\section{c. Phase locking to the seasonal cycle}

The phase-locked structure of the El Niño/WWV phase diagram in Fig. 5 follows from the trajectory physics in the next to last paragraph of section 5a and previous work on the phase locking of El Niño/La Niña to the seasonal cycle, specifically the result that El Niños and La Niñas tend to grow from April to December and then decrease in amplitude from December to March. The growth is explained by a coupled ocean-atmosphere instability at the edge of the western Pacific warm pool and the maximum amplitude at the end of the year by the shift of zonal equatorial wind anomalies southward of the equator at the end of the calendar year [see, e.g., the summary in sections 3 and 4 of the review paper Clarke (2014)]. Briefly, for the El Niño case, a small eastward displacement of the equatorial warm pool results in heavier rain to the east of the mean longitude of the warm pool edge. Consistent with the physics of Clarke (1994), anomalous deep convective rainfall generates westerly wind anomalies. These anomalies push the equatorial warm pool edge farther to the east, generating more anomalous convection and farther eastward movement, that is, a coupled ocean-atmosphere instability occurs. The instability usually terminates at the end of the calendar year because then the wind anomalies move south of the equator (Harrison 1987; McGregor et al. 2013; see also Fig. 9) as they follow the warmer water developing south of the equator in the Southern Hemisphere summer (Harrison and Vecchi 1999). Harrison and Vecchi noted that this movement of wind anomalies off the equator can terminate El Niño, and using a high resolution numerical model, McGregor et al. (2014) examined how the southward shift of equatorial wind anomalies affects El Niño. Below we link the Zhang and Clarke (2017) physics discussed in section 5a to seasonal El Niño phase locking caused by the southward movement of the zonal equatorial wind anomalies during the Southern Hemisphere summer.

Specifically, in the context of the 1.5-layer model, the Zhang and Clarke (2017) theory suggests that

$$
\eta_{E}(t)=\left(\rho_{1} H_{1} g\right)^{-1} \int_{0}^{L}(x / L)^{1 / 2} \tau^{x}(x, 0, t) d x,
$$

a result that is in reasonable agreement with observation (see Fig. 10). Figure 11 shows that, when the westerly equatorial wind anomalies move south of the equator at the end of the calendar year and beginning of the next, $\tau^{x}$ on the equator decreases, and from (22) and the observations (Fig. 11) positive $\eta_{E}(t)$ decreases. According to (17), this decrease in $\eta_{E}$ toward zero should result in a westward anomalous flow in the eastern equatorial Pacific. In fact, if we zonally average (17) in the eastern 


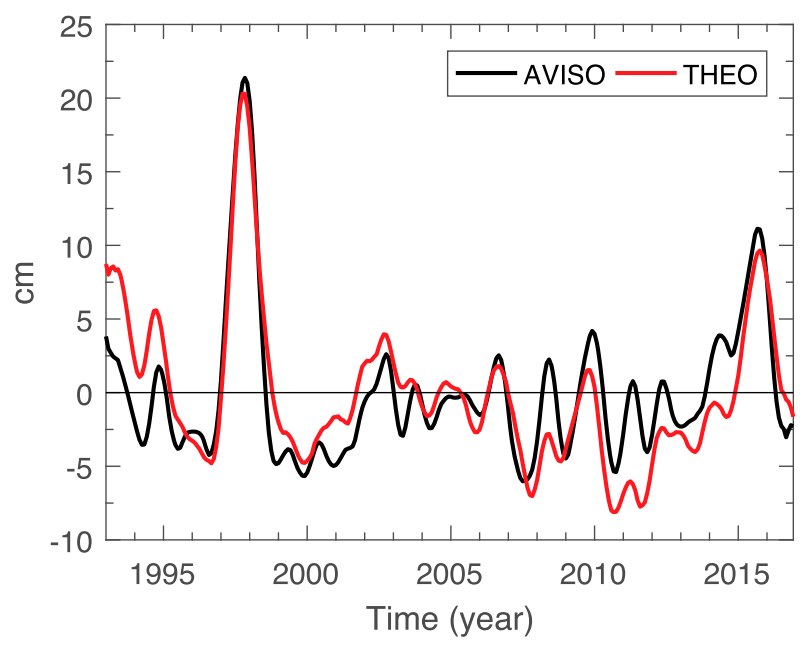

FIG. 10. Interannual $\eta_{E}$ (black) from AVISO SSH on the equator at $277.33^{\circ} \mathrm{E}$ compared with theoretical $\eta_{E}$ (red) from (22). The observed $\eta_{E}$ has been detrended with the global mean sea level trend of $2.8 \mathrm{~mm} \mathrm{yr}^{-1}$ and then filtered with the 11-point Trenberth (1984) linear interannual filter. The correlation between the interannual time series is $r=0.85, r_{\text {crit }}(95 \%)=0.40$ with regression coefficient unity obtained by choosing $H_{1}=108 \mathrm{~m}$.

equatorial Pacific from $140^{\circ} \mathrm{W}(x=a)$ to $80^{\circ} \mathrm{W}(x=L)$ along the equator, we obtain

$$
u_{\mathrm{E} \_ \text {Eq_Pac }}=(L-a) g c^{-2}\left(\eta_{E t}+\lambda \eta_{E}\right) .
$$

Using the observed $\eta_{E}$ from AVISO in Fig. 10 we obtain the $u_{\text {E_Eq_Pac }}$ currents in Fig. 12 . There is indeed westward anomalous flow in the El Niño case. Note that this westward flow negative feedback signal is the largest contributor to $u$ even in the central and western Pacific (see Fig. 4 of Zhang and Clarke 2017), and so tends to push the warm pool back westward. A similar westward upper ocean flow negative feedback signal has been identified from $20^{\circ} \mathrm{C}$ isotherm depth data by Chen et al. (2016).

The westward push may be strong enough for the warm pool to be displaced west of its mean position. Then a growing coupled ocean-atmosphere instability of opposite sign can develop in April/May as the warm pool is pushed anomalously westward by anomalous drying and easterly winds. These easterly winds will move off the equator near the end of the calendar year (see Fig. 9) so that $\eta_{E}$ is less negative, that is, $\partial \eta_{E} / \partial t$ is positive. This results in eastward (observed) or nearly zero anomalous flow (23) and results in the warm pool edge being moved back to, or possibly east of, its mean longitudinal position by June. This may or may not result in the generation of an El Niño.

Substitution of (17) into (13) enables us to discern how the equatorial current discussed above affects the WWV and the relationship between WWV and El Niño during

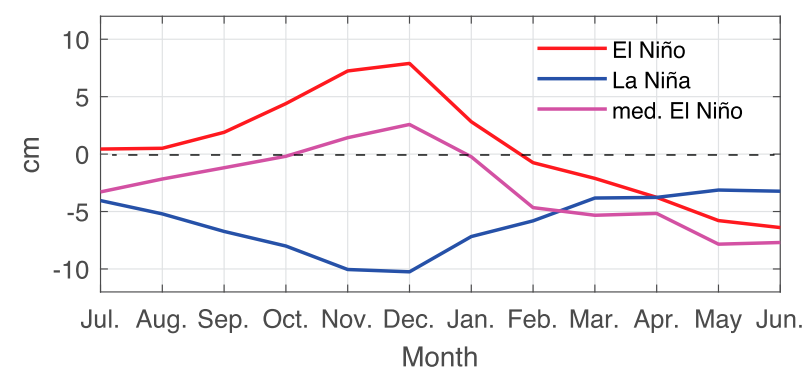

FIG. 11. Typical (since 1992) monthly sea level $\eta_{E}$ in the eastern equatorial Pacific during July-March of an El Niño year and the following April, May, and June (red). The corresponding average for La Niña is blue with magenta indicating El Niño $\eta_{E}$ with the huge 1997 and $2015 \mathrm{El}$ Niño years absent. The $\eta_{E}$ is based on satellite SSH at the equator and $82.5^{\circ} \mathrm{W}$. The eight El Niño years are 1994, 1997, 2002, 2004, 2006, 2009, and 2015, and the seven La Niña years are 1995, 1998, 1999, 2000, 2007, 2008, 2010, and 2011. "Typical" values of $\eta_{E}$ were found by a simple average.

the crucial time of transition from one El Niño year to the next. After integration with respect to $x$, we have

$$
\begin{aligned}
\bar{\eta}= & \eta_{E}-\int_{0}^{L}(x / L) \tau^{x} /\left(\rho_{1} H_{1} g\right) d x \\
& +\left[L^{2} /\left(3 c^{2}\right)\right](\partial / \partial t+\lambda)^{2} \eta_{E} .
\end{aligned}
$$

When the zonal wind stress anomalies move off the equator (see Fig. 9) and $\eta_{E}$ approaches zero, the second term on the RHS also approaches zero. Since $(\partial / \partial t+\lambda)^{2}$ $\eta_{\mathrm{E}} \sim \eta_{\mathrm{Ett}}+2 \lambda \eta_{\mathrm{Et}}+\lambda^{2} \eta_{\mathrm{E}}$, and since $\eta_{\mathrm{Ett}}$ behaves roughly like a negative constant times $\eta_{\mathrm{E}}$ for oscillatory
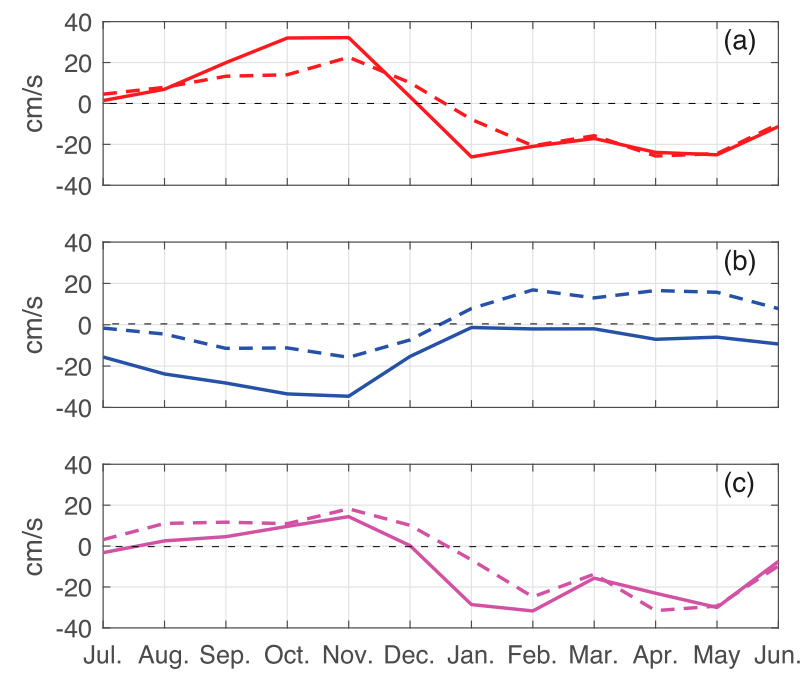

FIG. 12. As in the Fig. 11 composite, but for the anomalous eastward surface equatorial flow (solid) averaged between $140^{\circ}$ and $80^{\circ} \mathrm{W}$ using (17) with AVISO $\eta_{E}$ and the same color coding as in Fig. 11. The dashed curves are analogous observed eastward current anomalies but now using observed flows based on the OSCAR surface current data. 
variability like El Niño, the RHS of (24) approaches $2 \lambda \partial \eta_{E} / \partial t$ as $\eta_{E}$ approaches zero. Therefore, after there has been an El Niño at the beginning of the calendar year and $\eta_{E}$ is decreasing to zero, $\partial \eta_{\mathrm{E}} / \partial t$ will be $<0$ and, from the approximate version of (24) for $\eta_{E}$ small, $\bar{\eta}$ is negative. This is consistent with a discharge following an El Niño and the clockwise rotation of the (Niño-3.4, WWV) points in the phase diagram (see the top panel of Fig. 5). A similar argument can be given for $\bar{\eta}$ being positive after a La Niña, but the bottom panel of Fig. 5 suggests that this usually does not occur. We will explore this asymmetry in the next section.

\section{The asymmetry in the El Niño and La Niña phase diagrams}

As noted in the phase diagrams in Fig. 5, there is a marked difference in the El Niño and La Niña cases. As shown in section 2, consistent with the phase diagrams and regardless of the global warming, since 1873 large El Niños tend to be followed by La Niñas but large La Niñas tend to be followed by a La Niña rather than an El Niño. In this section we seek to understand this asymmetry using the physics of section 5 .

Figure 10 shows that $\eta_{E}$ is much larger in magnitude for large El Niños (1997 and 2015) than for large La Niñas (e.g., 1999 and 2007). Based on the factor $(x / L)^{1 / 2}$ in (22) and that the western equatorial Pacific warm pool edge is displaced eastward during El Niño [where $(x / L)^{1 / 2}$ is larger] and westward during La Niña [where $(x / L)^{1 / 2}$ is smaller], one might expect that this may be the reason why $\eta_{E}$ is larger in magnitude for large El Niños than large La Niñas. However, comparison of the RHS of (22) with a similar time series but with the factor $(x / L)^{1 / 2}$ omitted, and with both time series normalized by their respective standard deviations, shows that the relative size of the El Niño and La Niña amplitudes is almost the same so the $(x / L)^{1 / 2}$ factor has little effect. Thus, the main reason for the difference in amplitude in $\eta_{E}$ is that, as has been pointed out by Dommenget et al. (2013), the large El Niño wind stress anomalies tend to be much larger in magnitude than the corresponding large La Niña wind anomalies (see Fig. 13).

Larger amplitude $\eta_{E}$ during El Niño implies that $\partial \eta_{E} / \partial t$ and the anomalous westward equatorial current will be larger when the equatorial wind anomalies move south of the equator in accordance with the mechanism discussed at the end of section 5. Stronger negative feedback for El Niño than for La Niña suggests that the negative feedback is more likely to cause La Niña to follow an El Niño than El Niño to follow a La Niña. In fact, the negative feedback following a La Niña may be too weak to stop La Niña from persisting into the following year.

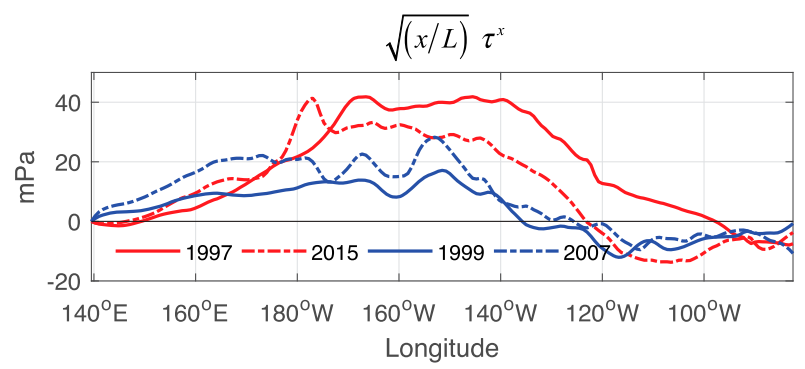

FIG. 13. The $(x / L)^{1 / 2}$ multiplied by the December zonal wind stress anomaly for the big El Niño years 1997 and 2015 and the big La Niña years 1999 and 2007. The La Niña zonal wind stress anomalies, which are mostly easterly, have been multiplied by -1 so that they are more easily compared with the mostly westerly El Niño wind stress anomalies. The month of December was chosen since this is when $\eta_{E}$ usually reaches its largest amplitude.

This is qualitatively consistent with the $r_{*}$ results in section 2 in that $r_{*}$ is negative for $Y(a+1)$ following $Y(a)$ corresponding to an El Niño and $r_{*}$ is positive for $Y(a+1)$ following an $Y(a)$ corresponding to a La Niña.

We also point out that there is another mechanism favoring a stronger negative feedback for extremely large El Niños. Vecchi and Harrison (2006) and Vecchi (2006) suggested an eastern equatorial Pacific El Niño termination mechanism dependent on the seasonal variation of the equatorial Trade winds there. Specifically, in the latter part of 1997 and until about April of 1998, the western Pacific warm pool and the associated westerly wind anomalies had penetrated east of $140^{\circ} \mathrm{W}$ and into the region affected by seasonal variations of the equatorial trade winds (see Fig. 14). As expected, the southward movement of the westerly wind anomalies in the central Pacific caused the $\eta_{E}$ anomaly to decrease and the eastern equatorial Pacific thermocline to rise to be near the surface. Even though the thermocline was nearer the surface, until April of 1998 the westerly wind anomaly reduced the easterly trade wind speed, inhibited vertical mixing, and the SST remained abnormally high. However, in May the seasonal trade wind strengthened enough to mix the shallow thermocline, decrease the SST and effectively result in a sudden retreat of the warm pool. Vecchi (2006) pointed out that this mechanism also operated for the very large $1982 \mathrm{El}$ Niño and likely other very large El Niños. This mechanism was not effective for the recent large $2015 \mathrm{El}$ Niño because the warm pool did not penetrate as far to the east as in 1982 and 1997.

\section{Decadal changes in ENSO predictability by WWV}

Tang and Deng (2010), McPhaden (2012), Horii et al. (2012), and Bunge and Clarke (2014) have all pointed out that the lead of WWV over El Niño has changed on a 

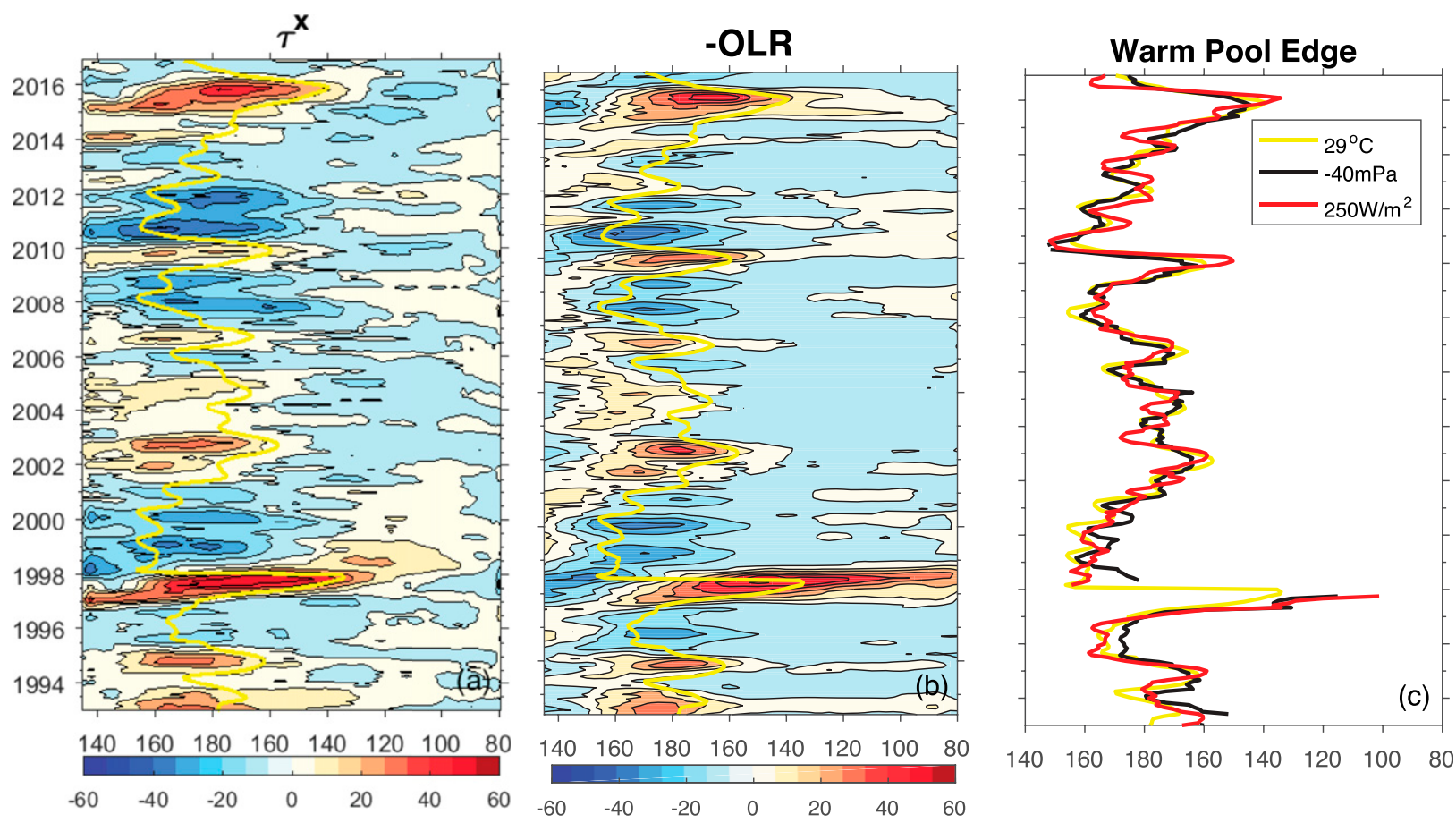

FIG. 14. (a) Time-longitude plot of westerly wind stress anomalies $(\mathrm{mPa})$ along the equator in the equatorial Pacific with the thick yellow line denoting the equatorial location of the $29^{\circ} \mathrm{C}$ isotherm, a proxy for the eastern edge of the warm/fresh pool; (b) as in (a), but for -OLR; and (c) equatorial longitudinal location of the $29^{\circ} \mathrm{C}$ isotherm (yellow), $-40-\mathrm{mPa}$ eastward equatorial wind stress isoline (black), and the $250 \mathrm{~W} \mathrm{~m}^{-2}$ OLR isoline (red). The break in the red and black curves near the end of 1997 occurs because the $-40-\mathrm{mPa}$ and $250 \mathrm{~W} \mathrm{~m}^{-2}$ values did not occur in the equatorial Pacific then. All data have been filtered with a 5-month running mean. The wind stress was averaged between $2.25^{\circ} \mathrm{S}$ and $2.25^{\circ} \mathrm{N}$, the OLR between $2.5^{\circ} \mathrm{S}$ and $2.5^{\circ} \mathrm{N}$, and the SST between $2^{\circ} \mathrm{S}$ and $2^{\circ} \mathrm{N}$. In (c), the correlation between the $29^{\circ} \mathrm{C}$ and $-40-\mathrm{mPa}$ time series is $r=0.89, r_{\text {crit }}(95 \%)=0.42$, between the $29^{\circ} \mathrm{C}$ and $250 \mathrm{~W} \mathrm{~m}^{-2}$ time series is $r=0.87, r_{\text {crit }}$ $(95 \%)=0.39$, and between the $-40-\mathrm{mPa}$ and $250 \mathrm{~W} \mathrm{~m}^{-2}$ time series is $r=0.87, r_{\text {crit }}(95 \%)=0.95$. The wind stress data are downloaded from https:/apps.ecmwf.int/datasets/data/interim-full-moda/levtype $=$ sfc/, the OLR data are available from https:/iridl.ldeo.columbia.edu/SOURCES/ .NOAA/.NCEP/.CPC/.GLOBAL/monthly/index.html?Set-Language=en, and the SST is downloaded from https:/www.esrl.noaa.gov/psd/data/ gridded/data.noaa.oisst.v2.html. [Adapted and updated from Zhang and Clarke (2015).]

decadal time scale. Bunge and Clarke (2014) provided evidence suggesting that (see Fig. 15) the decadal lead of WWV fluctuates in phase with decadal changes in ENSO. Specifically, for decades when the eastern equatorial edge of the warm pool on average is closer to the western ocean boundary (more La Niña-like conditions) the WWV lead over El Niño decreases, and for decades when it is farther from the western ocean boundary the lead increases.

The Bunge and Clarke results in Fig. 15 are in qualitative agreement with the 1.5-layer results presented earlier. Substitution of (22) into (13) gives

$$
\begin{aligned}
\bar{\eta}= & \int_{0}^{L}\left[(x / L)^{1 / 2}-(x / L)\right] \tau^{x}\left(\rho_{1} H_{1} g\right)^{-1} d x+g^{-1} \\
& \times \int_{0}^{L}(x / L)(\partial / \partial t+\lambda) u d x .
\end{aligned}
$$

The first integral on the RHS of (25) is positively correlated at zero lag with the El Niño index $\int_{0}^{L} \tau^{x} d x$, an expected correlation given that the weighting function $(x / L)^{1 / 2}-(x / L)$ is positive except at the boundaries where it is zero. On the other hand the integrand in the second integral on the RHS of (25) is the zonal equatorial flow acceleration that is weighted by the factor $x / L$ to the eastern Pacific where the zonal flow acceleration is an El Niño predictor (see section 5). Since the weighting factor $(x / L)^{1 / 2}-(x / L)$ in the first integral has a single maximum at $x / L=0.25$ in the western Pacific, we expect that for decades when the equatorial warm pool edge on average is closer to the western boundary, on average the zonal wind anomalies will be too. Thus, the first RHS integral will be enhanced relative to the second. Consequently, $\bar{\eta}$ will behave more like an El Niño index, decreasing its lead over El Niño/La Niña consistent with Fig. 15. Similarly in a decade where the warm pool edge is farther to the east, the first integral will be relatively less important and, consistent with Fig. 15, $\bar{\eta}$ and WWV will be better predictors. 

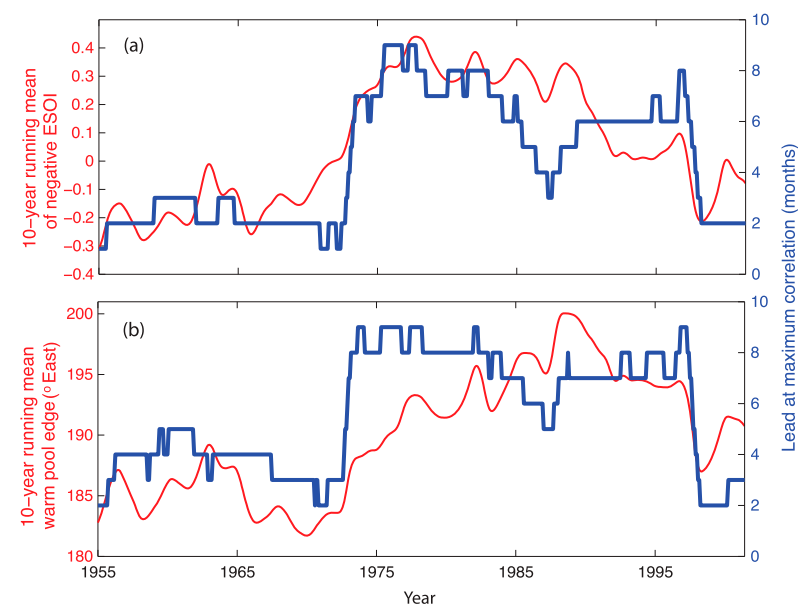

FIG. 15. (a) The 10-yr running mean of negative ESOI (red line) and lead at maximum correlation between the Kiritimati WWV index and negative ESOI (blue line). A positive lead means that the Kiritimati index leads negative ESOI. The 10-yr segments are labeled according to the starting year of the segment. (b) The 10-yr running mean of the zonal displacement of the $28.5^{\circ} \mathrm{C}$ isotherm, a proxy of the eastern edge of the warm pool (red line), and lead at maximum correlation between the Kiritimati index and the zonal $28.5^{\circ} \mathrm{C}$ isotherm displacement (blue line). A positive lead means that the Kiritimati WWV index leads the zonal $28.5^{\circ} \mathrm{C}$ isotherm displacement. The lead calculations were based on the monthly time series filtered with the Trenberth (1984) filter.

\section{Discussion and conclusions}

Jin's (1997a,b) recharge oscillator and the observational verification of WWV's ability to predict El Niño (Meinen and McPhaden 2000; Clarke and Van Gorder 2003) fundamentally changed the course of ENSO research. However, Jin's analysis did not have the benefit of more recent theoretical research and observations. Our analysis emphasizes that, because low frequency reflection at the eastern boundary can be described in sea level by long remotely forced Rossby waves with speed $\beta c^{2} / f^{2}$, sea level nearer the equator leads that farther from it, and therefore the meridional sea level gradient acts like a time derivative. Consequently, $u$ leads $\eta$ (Zhang and Clarke 2017), $\eta_{E}$ and hence eastern equatorial Pacific thermocline displacement and El Niño. Since $\bar{\eta}$ is of a form that tends to cancel the El Niño signal and enhance the eastern equatorial Pacific zonal flow acceleration $(\partial / \partial t+\lambda) u$ [see (25)], we suggest that the remotely forced eastern boundary Rossby wave physics is a key component of the WWV prediction of El Niño/La Niña.

Based on our analysis here and that summarized by Clarke (2014), we suggest the following basic dynamics for El Niño. A small displacement perturbation eastward of the equatorial Pacific warm pool edge in April/ May when the equatorial Pacific is seasonally warm results in enhanced warm water and deep convection east of the mean position of the warm pool edge. Deep convection generates westerly wind anomalies (Clarke 1994), which advect water eastward along the equator, mostly as a shallow $(50-70 \mathrm{~m})$ freshwater jet with meridional scale only $2^{\circ}-3^{\circ}$ of latitude (Zhang and Clarke 2015). The eastward advection causes a larger eastward displacement, more anomalous warm pool displacement east of the warm pool edge, further deep convection, that is, a growing coupled ocean-atmosphere instability results. The westerly wind stress anomalies also tilt the sea level up and the thermocline down in the eastern equatorial Pacific. The growing instability explains the persistence of ENSO variables (see, e.g., Fig. 3) from June to February.

The instability ends in the Southern Hemisphere summer when the westerly wind stress anomalies shift south of the equator (Harrison 1987) as they follow the warmer water south of the equator (Harrison and Vecchi 1999). When the wind anomalies move south of the equator, the equatorial winds are very weak and $\eta_{E}$ decreases toward zero in agreement with (22). This results in $\partial \eta_{E} / \partial t<0$ at the end of the El Niño year (typically the end of the calendar year and the few months of the new calendar year; Fig. 11), and an anomalous westward equatorial flow via long Rossby wave dynamics (section 5; Zhang and Clarke 2017). This flow influences the entire equatorial Pacific and causes the warm pool edge to be pushed back westward. If the anomalous westward flow pushes the warm pool back far enough, it may push it west of its mean position and initiate a coupled ocean-atmosphere instability of the opposite sign. We suggest that this mechanism provides an explanation of the tendency for La Niña to follow El Niño discussed in section 2. As explained in Zhang and Clarke (2017) and section 5, the WWV is directly related to the anomalous zonal flow and its acceleration, and as such leads El Niño.

La Niña develops via a coupled ocean atmospheric instability in a similar way to El Niño but with opposite sign, that is, the initial displacement of the warm pool edge is westward and there is anomalous drying and easterly winds during the instability. A similar negative feedback related to the shift of the wind anomalies south of the equator and $\partial \eta_{E} / \partial t$ also operates in this case, but it is usually smaller because $\eta_{E}$ typically changes by a smaller amount during La Niña than during El Niño (see section 6). Consequently the eastward current anomalies generated by $\partial \eta_{E} / \partial t>0$ in this case are often not strong enough to push the warm pool back east of its mean position and begin an El Niño in March/April/ May. This may be the reason for the observational result (section 2) that La Niña or weakly negative conditions tend to follow a La Niña. This asymmetry in El Niño/La Niña 
behavior is consistent with the breakdown of the clockwise rotation of the phase diagram (see Figs. 1, 5, 6).

Analysis in section 7 provides theoretical support for the decadal variations in the ability of WWV to predict El Niño/La Niña. During La Niña-like decades where the "mean" position of the warm pool edge is closer to the western boundary, $\bar{\eta}$ is relatively less strongly influenced by the zonal acceleration nonequilibrium flow, and WWV's ability to predict decreases. Conversely, during El Niño-like decades when the mean position of the warm pool edge is farther from the western boundary, WWV's ability to predict increases. These results are in agreement with the observational analysis of Bunge and Clarke (2014).

Acknowledgments. We thank the two anonymous reviewers of this manuscript for their helpful reviews which substantially improved this manuscript. We gratefully acknowledge the National Aeronautics and Space Administration for financial support (Grant NNX17AK28G). Any opinions, findings, and conclusions or recommendations expressed in here are those of the authors and do not necessarily reflect the views of the funding organization.

\section{APPENDIX A}

\section{Asymmetry in EI Niño/La Niña Sequences since 1873}

The phase diagrams in Fig. 5 and previous work by Larkin and Harrison (2002), and Okumura and Deser (2010) suggest that there is a tendency for strong El Niños to be followed the next year by a La Niña (or at least negative Niño-3.4) while strong La Niñas are followed by weak La Niña (or at least negative Niño-3.4). The long period since 1873 covers a time when significant global warming occurred and affects the "mean" background state on which El Niño and La Niña anomalies are calculated. We therefore did two calculations, one based on monthly Niño-3.4 values under the fixed mean defined in the first paragraph of the introduction, and the other calculation by extracting a global warming Niño-3.4 "signal" having the same approximate bilinear shape as the global warming SST signal (see Fig. A1). Specifically from 1873 to 1949 we subtracted a mean of the record and for the mean from 1950 to 2017 we removed a linear fit with the starting value the mean at the end of 1949. In our calculations we used the Bunge and Clarke (2009) dataset which has been verified by physically equivalent time series using independent observed data.

To test the hypothesis that an El Niño year is often followed by a La Niña year, we calculated $S(m) Y(a)$ as

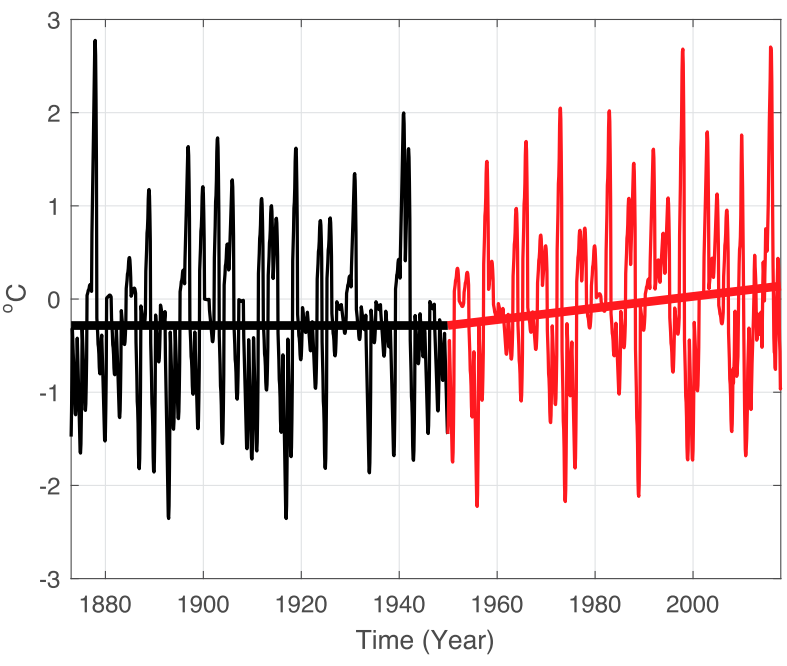

FIG. A1. Time series of Niño-3.4 monthly anomaly based on Bunge and Clarke (January 1873-February 2008) and extended to 2017 December by using NOAA Niño-3.4 index. The thick black and red lines show the bilinear least squares fit.

in (1) for the complete raw Niño-3.4 record and then calculated the statistic

$$
\begin{aligned}
r_{*}= & \sum_{\text {all El Niño }} Y(a) Y(a+1) /\left\{\sum_{\text {all El Niño }}[Y(a)]^{2}\right\}^{1 / 2} \\
& \times\left\{\sum_{\text {all El Niño }}[Y(a+1)]^{2}\right\}^{1 / 2}
\end{aligned}
$$

where $a$ is an El Niño year and $a+1$ is the year following it. Note that $r_{*}$ differs from the usual lagged autocorrelation $r$ in that $Y(a)$ has a nonzero positive mean since $a$ here corresponds only to El Niño years. Also note that if it were always true that an El Niño is followed by a La Niña and $Y(a+1)=-\alpha Y(a)$ for all El Niño years $Y(a)$, then from (A1) we have $r_{*}=-1$. As noted in the first paragraph of section 2 , for El Niño we chose those years $a$ such that $S(m) Y(a) \geq 0.55^{\circ} \mathrm{C}$ for the 3 months with largest $S(m)$. Similarly for La Niña this quantity is $\leq-0.55^{\circ} \mathrm{C}$. Under this definition there were $43 \mathrm{El}$ Niños and 48 La Niñas from January 1873 to December 2016 based on the fixed modern mean January 1993 to December 2016; under the bilinear mean that takes into account global warming (see above), there were $44 \mathrm{El}$ Niños and 49 La Niñas.

For the El Niño case our calculations gave $r_{*}=-0.1877$ ( $p=12.02 \%$ ) for the fixed mean period and $r_{*}=-0.2350$ $(p=6.65 \%)$ for the global warming mean calculations. The $p$ value is the probability that a value of $r_{*}$ equal to or less than the calculated negative value could have been obtained by chance. This value was estimated from a frequency distribution of $r_{*}$ found by calculating $10000 r_{*}$ values with $Y(a+1)$ chosen randomly with 
replacement from any of the 144 possible $Y$ for the April 1873-March 2017 period available from Niño-3.4 data. The small $p$ values suggest that El Niño years tend to be followed by a year with negative $Y$. This is consistent with El Niño phase diagram (Fig. 5a) suggesting that typically an El Niño is followed by a La Niña.

On the other hand, for the La Niña cases $r_{*}=0.1924$ $(p=10.00 \%)$ for the fixed mean case and $r_{*}=0.1645$ $(p=12.96 \%)$ for the case when the mean is adjusted for global warming. This is in marked contrast to the $\mathrm{El}$ Niño case as $r_{*}$ is of opposite in sign. The small $p$ values indicate that the probability that the value $r_{*}$ obtained is at least as large as that found by chance is small. In other words, $r_{*}$ is more likely positive than negative, suggesting that the year following a La Niña is likely to be another year with negative $Y$.

We wondered if the above tendency for a negative $Y$ year to follow both El Niño and La Niña would be more apparent if we considered just the strong El Niño and La Niñas. We therefore increased the threshold from $0.55^{\circ}$ to $1^{\circ} \mathrm{C}$, that is, $S(m) Y(a) \geq 1^{\circ} \mathrm{C}$ for an El Niño and $S(m)$ $Y(a) \leq-1{ }^{\circ} \mathrm{C}$ for a La Niña. Under this definition there were 30 strong El Niños and 30 strong La Niñas from January 1873 to December 2016 based on the fixed modern mean January 1993 to December 2016; under the bilinear mean that takes into account global warming (see above), there were 28 strong El Niños and 29 strong La Niñas.

Our results showed that the tendency for a negative $Y$ year to follow both an El Niño and a La Niña strengthened when larger amplitude El Niños and La Niñas were considered; the magnitude of $r_{*}$ became larger and $p$ smaller in all cases. Specifically, for the strong El Niño case $r_{*}=-0.4102(p=1.6 \%)$ for the fixed mean period and $r_{*}=-0.4154(p=1.8 \%)$ for the global warming mean calculations; for the strong La Niña cases $r_{*}=0.3027(p=5.74 \%)$ for the fixed mean case and $r_{*}=0.3057(p=6.15 \%)$ for the case when the mean is adjusted for global warming.

\section{APPENDIX B}

\section{Analytical Solution in the Eastern Equatorial Pacific}

As mentioned in section 5a of the main text, Cane and Moore (1981) derived an analytical solution for the pressure and velocity fields near a meridional eastern ocean boundary. The nondimensional Cane and Moore solution is given by their (12). For our 1.5-layer model the dimensional solution for the sea level is, with $f=\beta y$,

$$
\begin{aligned}
\eta= & c^{2} g^{-1}[\cos (2 s)]^{1 / 2} \\
& \times \exp \left[0.5 i f^{2} c^{-1} \beta^{-1} \tan (2 s)\right] \exp (i \omega t),
\end{aligned}
$$

where, for the case with dissipation

$$
s=(\omega-i \lambda)(x-L) / c .
$$

The parameter $s$ is small in magnitude at interannual frequencies (see section 5a of the main text). For small $|s|$ (B1) can be written

$$
\begin{aligned}
\eta= & c^{2} g^{-1}\left(1-s^{2}\right) \exp (i \omega t) \exp \left(i f^{2} c^{-1} \beta^{-1} s\right) \\
& \times \exp \left(-4 i f^{2} c^{-1} \beta^{-1} s^{3} / 3\right)
\end{aligned}
$$

or, with error the larger of $\left(\left|s^{2}\right|,\left|-4 i f^{2} c^{-1} \beta^{-1} s^{3} / 3\right|\right)$, and using (B2),

$$
\begin{aligned}
\eta= & c^{2} g^{-1} \exp \left\{i \omega\left[t+f^{2} c^{-2} \beta^{-1}(x-L)\right]\right\} \\
& \times \exp \left[\lambda f^{2} c^{-2} \beta^{-1}(x-L)\right] .
\end{aligned}
$$

In the region of interest within $10^{\circ}$ of latitude of the equator the error is dominated by $\left|s^{2}\right|=\left(\lambda^{2}+\omega^{2}\right)^{2}(L-x)^{2} / c^{2}$. Thus, for all frequencies $\omega$ satisfying $\left|s^{2}\right| \ll 1, \eta$ is in the form of a long, nondispersive Rossby wave propagating westward at a speed $\gamma=\beta c^{2} f^{-2}$ and decaying westward with an $e$-folding decay scale $\gamma \lambda^{-1}$, the distance such a nondispersive Rossby wave travels in the decay time $\lambda^{-1}$. Note that (B4) corresponds to the solution for an individual Fourier component of frequency $\omega$; summing all the Fourier components gives the time domain solution $\eta(x, y, t)$. At the eastern boundary $x=L$, $\eta=\eta_{E}(t)$ and the Fourier component from (B4) is $c^{2} g^{-1} \exp (i \omega t)$. Since all the frequencies $\omega$ in (B4) have the same phase lag $(x-L) / \gamma$ in time and same decay $\exp [\lambda(x-L) / \gamma]$ relative to $\eta_{E}(t)$, we must have that

$$
\eta(x, y, t)=\eta_{E}[t+(x-L) / \gamma] \exp [\lambda(x-L) / \gamma],
$$

which is (15) of the text. This long Rossby wave result was also obtained for a similar low-frequency limit using a perturbation approach (Clarke 1983), which was generalized by Fedorov (2010) and Clarke (2010) to include wind forcing.

\section{REFERENCES}

Bunge, L., and A. J. Clarke, 2009: A verified estimation of the El Niño index Niño-3.4 since 1877. J. Climate, 22, 3979-3992, https://doi.org/10.1175/2009JCLI2724.1.

— and - 2014: On the warm water volume and its changing relationship with ENSO. J. Phys. Oceanogr., 44, 1372-1385, https://doi.org/10.1175/JPO-D-13-062.1.

Cane, M. A., and D. W. Moore, 1981: A note on low-frequency equatorial basin modes. J. Phys. Oceanogr., 11, 15781584, https://doi.org/10.1175/1520-0485(1981)011<1578: ANOLFE $>2.0 . C O ; 2$.

Chen, H.-C., Z.-Z. Hu, B. Huang, and C. H. Sui, 2016: The role of reversed equatorial zonal transport in terminating an ENSO 
event. J. Climate, 29, 5859-5877, https://doi.org/10.1175/JCLID-16-0047.1.

Clarke, A. J., 1983: The reflection of equatorial waves from ocean boundaries. J. Phys. Oceanogr., 13, 1193-1207, https://doi.org/ 10.1175/1520-0485(1983)013<1193:TROEWF>2.0.CO;2.

__ 1992: Low frequency reflection from a non-meridional eastern ocean boundary and the use of coastal sea level to monitor eastern Pacific equatorial Kelvin waves. J. Phys. Oceanogr., 22, 163-183, https://doi.org/10.1175/1520-0485(1992)022<0163: LFRFAN $>2.0 . \mathrm{CO} ; 2$.

1994: Why are surface equatorial ENSO winds anomalously westerly under anomalous large-scale convection? J. Climate, 7 , 1623-1627, https://doi.org/10.1175/1520-0442(1994)007<1623: WASEEW $>2.0 . \mathrm{CO} ; 2$.

- 2008: An Introduction to the Dynamics of El Niño and the Southern Oscillation. Academic Press, 324 pp.

_ 2010: Analytical theory for the quasi-steady and low frequency equatorial ocean response to wind forcing: The "tilt" and "warm water volume" modes. J. Phys. Oceanogr., 40, 121137, https://doi.org/10.1175/2009JPO4263.1.

_- 2014: El Niño physics and El Niño predictability. Annu. Rev. Mar. Sci., 6, 79-99, https://doi.org/10.1146/annurev-marine010213-135026.

—_, and A. Lebedev, 1996: Long-term changes in the equatorial Pacific trade winds. J. Climate, 9, 1020-1029, https://doi.org/ 10.1175/1520-0442(1996)009<1020:LTCITE > 2.0.CO;2.

__, and S. Van Gorder, 2003: Improving El Niño prediction using a space-time integration of Indo-Pacific winds and equatorial Pacific upper ocean heat content. Geophys. Res. Lett., 30, 2003, https://doi.org/10.1029/2002GL016673.

—, and - 2013: On fitting a straight line to data when the "noise" in both variables is unknown. J. Atmos. Oceanic Technol., 30, 151-158, https://doi.org/10.1175/JTECH-D-12-00067.1.

,-- , and G. Colantuono, 2007: Wind stress curl and ENSO discharge/recharge in the equatorial Pacific. J. Phys. Oceanogr., 37, 1077-1091, https://doi.org/10.1175/JPO3035.1.

Deser, C., and J. M. Wallace, 1990: Large-scale atmospheric circulation features of warm and cold episodes in the tropical Pacific. J. Climate, 3, 1254-1281, https://doi.org/10.1175/15200442(1990)003<1254:LSACFO>2.0.CO;2.

Dommenget, D., T. Bayr, and C. Frauen, 2013: Analysis of the nonlinearity in the pattern and time evolution of El Niño Southern Oscillation. Climate Dyn., 40, 2825-2847, https://doi.org/ 10.1007/s00382-012-1475-0.

Ebisuzaki, W., 1997: A method to estimate the statistical significance of a correlation when the data are serially correlated. J. Climate, 10, 2147-2153, https://doi.org/10.1175/ 1520-0442(1997)010<2147:AMTETS > 2.0.CO;2.

Fedorov, A. V., 2010: Ocean response to wind variations, warm water volume, and simple models of ENSO in the low-frequency approximation. J. Climate, 23, 3855-3873, https://doi.org/10.1175/ 2010JCLI3044.1.

Harrison, D. E., 1987: Monthly mean island surface winds in the central tropical Pacific and El Niño events. Mon. Wea. Rev., 115, 3133-3145, https://doi.org/10.1175/1520-0493(1987)115<3133: MMISWI $>2.0 . \mathrm{CO} ; 2$.

— Geophys. Res. Lett., 26, 1593-1596, https://doi.org/10.1029/ 1999GL900316.

Horii, T., I. Ueki, and K. Hanawa, 2012: Breakdown of ENSO predictors in the 2000s: Decadal changes of recharge/discharge-SST phase relation and atmospheric intraseasonal forcing. Geophys. Res. Lett., 39, L10707, https://doi.org/10.1029/2012GL051740.
Jin, F.-F., 1997a: An equatorial ocean recharge paradigm for ENSO. Part I: Conceptual model. J. Atmos. Sci., 54, 811-829, https:// doi.org/10.1175/1520-0469(1997)054<0811:AEORPF>2.0.CO;2.

_ 1997b: An equatorial ocean recharge paradigm for ENSO. Part II: A stripped-down coupled model. J. Atmos. Sci., 54, 830-847, https://doi.org/10.1175/1520-0469(1997)054<0830: AEORPF $>2.0 . \mathrm{CO} ; 2$.

Kessler, W. S., 2002: Is ENSO a cycle or a series of events? Geophys. Res. Lett., 29, 2125, https://doi.org/10.1029/2002GL015924.

Larkin, N. K., and D. E. Harrison, 2002: ENSO warm (El Niño) and cold (La Niña) event life cycles: Ocean surface anomaly patterns, their symmetries, asymmetries, and implications. J. Climate, 15, 1118-1140, https://doi.org/10.1175/1520-0442(2002)015<1118: EWENOA $>2.0 . \mathrm{CO} ; 2$.

McGregor, S., N. Ramesh, P. Spence, M. H. England, M. J. McPhaden, and A. Santoso, 2013: Meridional movement of wind anomalies during ENSO events and their role in event termination. Geophys. Res. Lett., 40, 749-754, https://doi.org/10.1002/grl.50136.

_, P. Spence, F. U. Schwarzkopf, M. H. England, A. Santoso, W. S. Kessler, A. Timmermann, and C. W. Böning, 2014: ENSO-driven interhemispheric Pacific mass transport. J. Geophys. Res. Oceans, 119, 6221-6237, https://doi.org/10.1002/2014JC010286.

McPhaden, M. J., 2012: A 21st century shift in the relationship between ENSO SST and warm water volume anomalies. Geophys. Res. Lett., 39, L09706, https://doi.org/10.1029/2012GL051826.

Meinen, C. S., and M. J. McPhaden, 2000: Observations of warm water volume changes in the equatorial Pacific and their relationship to El Niño and La Niña. J. Climate, 13, 3551-3559, https://doi.org/ 10.1175/1520-0442(2000)013<3551:OOWWVC > 2.0.CO;2.

Neske, S., and S. McGregor, 2018: Understanding the warm water volume precursor of ENSO events and its Interdecadal variation. Geophys. Res. Lett., 45, 1577-1585, https://doi.org/ 10.1002/2017GL076439.

Okumura, Y. M., and C. Deser, 2010: Asymmetry in the duration of El Niño and La Niña. J. Climate, 23, 5826-5843, https://doi.org/ 10.1175/2010JCLI3592.1.

Tang, Y., and Z. Deng, 2010: Tropical Pacific upper ocean heat content variations and ENSO predictability during the period from 1881-2000. Advances in Geosciences, Vol. 18, J. Gan, Ed., World Scientific, 87-108.

Thual, S., B. Dewitte, N. Ayoub, and O. Thual, 2013: An asymptotic expansion for the recharge-discharge model of ENSO. J. Phys. Oceanogr., 43, 1407-1416, https://doi.org/10.1175/JPO-D-12-0161.1.

Trenberth, K. E., 1984: Signal versus noise in the Southern Oscillation. Mon. Wea. Rev., 112, 326-332, https://doi.org/10.1175/ 1520-0493(1984)112<0326:SVNITS > 2.0.CO;2.

Vecchi, G. A., 2006: The termination of the 1997-98 El Niño. Part II: Mechanisms of atmospheric change. J. Climate, 19, 26472664, https://doi.org/10.1175/JCLI3780.1.

_ , and D. E. Harrison, 2006: The termination of the 1997-98 El Niño. Part I: Mechanisms of oceanic change. J. Climate, 19, 2633-2646, https://doi.org/10.1175/JCLI3776.1.

Walker, G. T., 1924: Correlation in seasonal variations of weather. IX. A further study of world weather. Mem. Indian Meteor. Dep., 24 (9), 275-332.

Zhang, X., and A. J. Clarke, 2015: Observations of interannual equatorial fresh water jets in the western equatorial Pacific. J. Phys. Oceanogr., 45, 2848-2865, https://doi.org/10.1175/ JPO-D-14-0245.1.

— , and — 2017: On the dynamical relationship between equatorial Pacific surface currents, zonally averaged equatorial sea level, and El Niño prediction. J. Phys. Oceanogr., 47, 323-337, https://doi.org/10.1175/JPO-D-16-0193.1. 